\title{
DOES TIMING OF AXON OUTGROWTH INFLUENCE INITIAL RETINOTECTAL TOPOGRAPHY IN XENOPUS? ${ }^{1}$
}

\author{
CHRISTINE E. HOL'T ${ }^{2}$
}

\author{
Departmenl of Biology, University of California San Diego, La Jolla, California 92093 and The University Laboratory of \\ Physiology, Oxford University, Parks Road, Oxford OX1 3PT, United Kingdom
}

Received August 29, 1983; Revised October 28, 1983; Accepted November 2, 1983

\begin{abstract}
The question of whether timing is involved in generating the topographic organization of the earliest embryonic projection from the retina to the tectum has been examined in Xenopus laevis.

First, the normal schedule of axonal outgrowth from the retina to the tectum was characterized. Groups of axons originating from either dorsal or ventral extremes of the retina were labeled by in vitro incubation of sectors (one-quarter to one-third) of eye primordia in $\left[{ }^{3} \mathrm{H}\right]$ proline and their time courses of outgrowth were determined using light microscope autoradiography. Comparisons of the growth of dorsal and ventral nerve fiber populations showed that those from the dorsal retina leave the eye first, grow along the optic pathway, and reach the tectum roughly $6 \mathrm{hr}$ ahead of those from the ventral retina. This stereotyped sequence of outgrowth schedules the development of the initial retinotectal map: first the ventrolateral tectum receives input from the dorsal retina (stage 37/38), and then the dorsomedial part receives input from ventral retina (stage 40).

Second, to test whether the accurate timing of axon outgrowth and target invasion defines the spatial ordering of the earliest connections, the normal schedule of retinal fiber outgrowth was altered by substituting dorsal halves of young stage 21 eye primordia, labeled with $\left[{ }^{3} \mathrm{H}\right]$ proline, for those in older stage 27 embryos. These heterochronic transplants resulted in retarded outgrowth from the dorsal retina such that the original pioneer fibers reached the tectum at least $9 \mathrm{hr}$ later than normal, arriving after ventral retinal fibers, thereby reversing the normal sequence of tectal invasion. Despite this, the initial pattern of tectal innervation remained spatially normal. It is concluded that the retinotectal map is generated not by the temporal sequence of retinal axon outgrowth but, rather, by selective means of neuronal recognition.
\end{abstract}

In lower vertebrate embryos, retinal axons grow to the contralateral tectum of the midbrain where they synapse in a continuously ordered manner forming a topographic map of the visual world. One hypothesis about how ordered patterns of neural connections become assembled during development is that axons are guided to their synaptic targets by unique and matching cytochemical labels (Sperry, 1963). In contrast, Horder and Martin (1978) suggest that the accurate timing and spatial or-

\footnotetext{
${ }^{1}$ This work was supported by grants from the McKnight Foundation (United States) and the Medical Research Council (United Kingdom). Bill Harris provided valuable discussions and advice throughout the study. I wish to thank him, Ian Thompson, and John Scholes for helpful criticisms of the manuscript. I am grateful to Tracy Smith and Nancy Gallenson for technical assistance and to Nick Spitzer's laboratory for providing Xenopus eggs.

"Correspondence should be sent to the Department of Biology, B022, University of California, San Diego, La Jolla, CA 92093.
}

dering of normal developmental events is sufficient for accurate map formation. Several factors have been shown to influence axon outgrowth in vitro, including mechanical forces (for reviews see Bray, 1982; Letourneau, 1982), diffusible agents (Gunderson and Barrett, 1980), and cell surface cues (Bonhoeffer and Huf, 1980, 1982), yet the specific involvement of these factors in neuronal mapping in vivo is unknown. The intention of the present study was to examine the influence of a normal developmental constraint, the temporal schedule of axon outgrowth and target innervation, on the establishment of topographic order in the initial retinotectal projection.

The orderly arrangement of axons within neural pathways in many vertebrate and invertebrate species suggests that spatiotemporal factors might be important in the formation of topographic maps in the central nervous system. In fish and amphibians the organization of the optic nerve and tract is retinotopic (Roth, 1974; Scalia and Fite, 1974; Scholes, 1979; Rusoff and Easter, 1980; 
Easter et al., 1981; Fawcett, 1981; Fujisawa et al., 1981; but see Scalia and Arango, 1983), and because the retina grows throughout life by adding new ganglion cells around the ciliary margin (Hollyfield, 1971; Straznicky and Gaze, 1971; Johns, 1977), a gradient of cell ages exists across the retinal radius from the oldest at the center to the youngest at the periphery. The chronology of birth dates is reflected in the organization of the pathway (Dawnay, 1979; Scholes, 1979; Bunt, 1982; Cima and Grant, 1982; Torrealba et al., 1982). In Xenopus, for example, the newest fibers travel closest to the pia in the optic tract (Gaze and Grant, 1978) and along the most ventral portion of the optic nerve (Cima and Grant, 1982). This orderly recruitment of optic fibers led to the idea that continuous maps can be formed on a "first come, first served" basis (Bunt and Horder, 1977; Bunt et al., 1978). It was suggested that the first axons that grow out of the eye synapse with the first cells they encounter in the tectum so that later growing axons are constrained to occupy the next available sites (Bunt et al., 1978; Horder and Martin, 1978; Bodick and Levinthal, 1980; Rager, 1980; Cima and Grant, 1982). The sole requirements of this scheme for forming a topographic map are simply that fibers grow out of the eye and invade the tectum in a sequence which matches the development of the map and that they preserve their neighbor relations as they grow (see Scholes, 1979). Indeed, the finding that maps tend to be disordered during the initial stages of optic nerve regeneration (Gaze and Jacobson, 1963; Gaze and Keating, 1970; Meyer, 1980; Fujisawa et al., 1982) where, in contrast with normal development, a large number of cut nerves reinnervate the tectum at about the same time rather than sequentially, lends support to this idea.

Timing has been invoked as a plausible mechanism for the formation of patterned nerve connections in other systems which display a stereotyped schedule of development, such as the invertebrate visual system (Anderson, 1978; Macagno, 1978), the dentate gyrus (Gottlieb and Cowan, 1972), and the neuromuscular system of the vertebrate limb (Horder, 1978; Jacobson, 1978). Also, differences in the times of arrival of retinal axons in the lateral geniculate nucleus of the fetal cat have been suggested to correlate with the size and lamination pattern of their terminal territories in the adult (Cooper and Pettigrew, 1979; Shatz, 1983; Walsh et al., 1983).

Experiments designed to perturb the normal sequence of developmental events and thereby test directly the involvement of timing support differing conclusions. In the invertebrate eye, manipulations which altered the normal time of axon outgrowth with respect to target tissue maturity, such as rotations and heterochronic grafts of pieces of embryonic photoreceptor tissue (Anderson, 1978; Nowell, 1981) and photoreceptor retardation (Macagno, 1981), show that connections within the optic lobe are made according to a time-dependent rather than a chemoaffinity mechanism. By contrast, timing is clearly not important in establishing the spatially restricted pattern of innervation of the amphibian Mauthner cell, since it forms despite delayed or precocious innervation (Leber and Model, 1981, 1982). Similarly, sensory axons from supernumerary cerci in the cricket make appropriate central connections despite growing in several weeks late (Murphey et al., 1983). Whether ordering at the dendritic level relates to the problem of topographic mapping, however, is not clear.

Feldman et al. (1971) have shown that if the whole retinal input to the tectum in Xenopus is delayed by unilateral embryonic eye removal and deflection of the remaining optic nerve several months later, then a normal retinotectal map becomes established. This study examined the regenerated projection some months after its initial establishment, and since regenerated maps are more disordered initially (Gaze and Keating, 1970; Meyer, 1980; Fujisawa et al., 1981, 1982) than are developing ones (Holt, 1983; Holt and Harris, 1983), the issue of timing in relation to the development of topographic order, the concern of the present study, was not addressed. The experiments of Lance-Jones and Landmesser $(1980,1981 \mathrm{a}, \mathrm{b})$ on the development of peripheral nerve connections indicate that a model based solely on mechanical constraints (Horder, 1978; Jacobson, 1978) is unlikely to account for the specific pattern of limb innervation. Nevertheless, a systematic examination of the temporal order of motoneuron axon outgrowth after experimentation was not made in these studies, so that a role for temporal factors could not be completely excluded. For instance, if the time of axon outgrowth was an autonomous property of motoneurons, then a model based on the principle of "first come, first served" (Bunt et al., 1978) could still have operated to give the normal patterns of innervation seen after small cord reversals (see Lance-Jones and Landmesser, 1980).

To test the influence of timing in a definitive way one needs: (1) a system in which the nerve connections are formed in a developmental sequence which correlates with and thus might account for their spatial organization, (2) a way of experimentally peturbing the temporal order of axon outgrowth, and (3) a method of marking growing nerve fibers so that their time course of outgrowth can be monitored and their places of termination can be identified. The present study achieves these requirements. The first part demonstrates that axons grow out of the Xenopus retina and arrive in the tectum in a defined temporal sequence which matches the topographic deployment of terminals in the early tectum. The second part describes heterochronic grafting experiments which delay the pioneering population of dorsal retinal fibers. These experiments result in a reversal of the normal sequence of tectal innervation and show that, despite this, the spatial ordering of the initial retinotectal map remains unaltered. Thus, the first retinal axons that grow into the tectal rudiment must recognize their proper termination domains by some active means; timing does not account for the initial order.

\section{Materials and Methods}

\section{Animals}

Eggs were obtained from adult Xenopus laevis stimulated to breed by treatment with human chorionic gonadotropin. Fertilized eggs were cleaned and separated on collection and placed in 10\% Holtfretter's solution. For the experiments on normal development (series I; see Fig. 1), embryos were raised at room temperature $\left(\sim 20^{\circ} \mathrm{C}\right)$. For the timing experiments (series II and IIIa, 


\section{SERIES I}

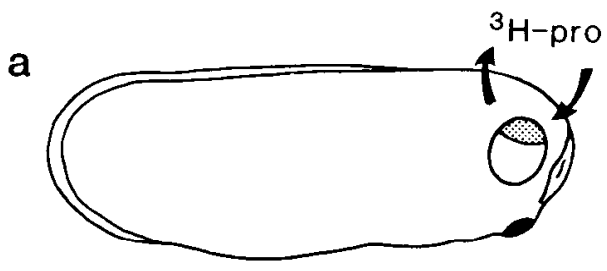

stage 26

b

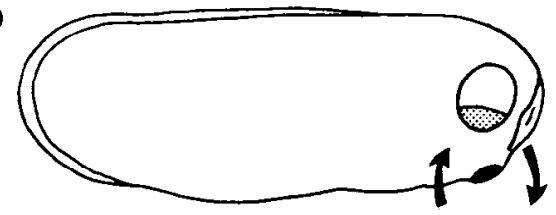

stage 26
${ }^{3} \mathrm{H}-\mathrm{pro}$

\section{SERIES \|I}

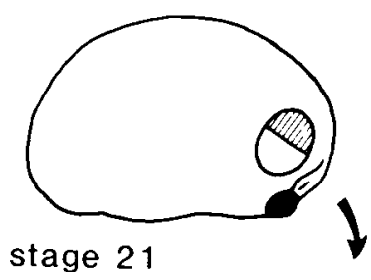

${ }^{3} \mathrm{H}-\mathrm{pro}$

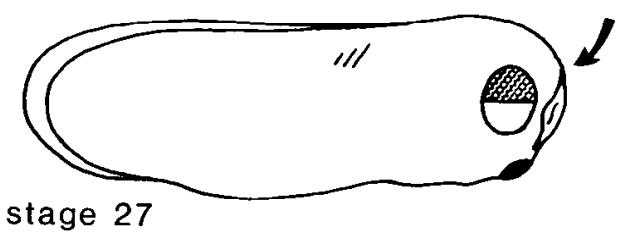

\section{SERIES III}
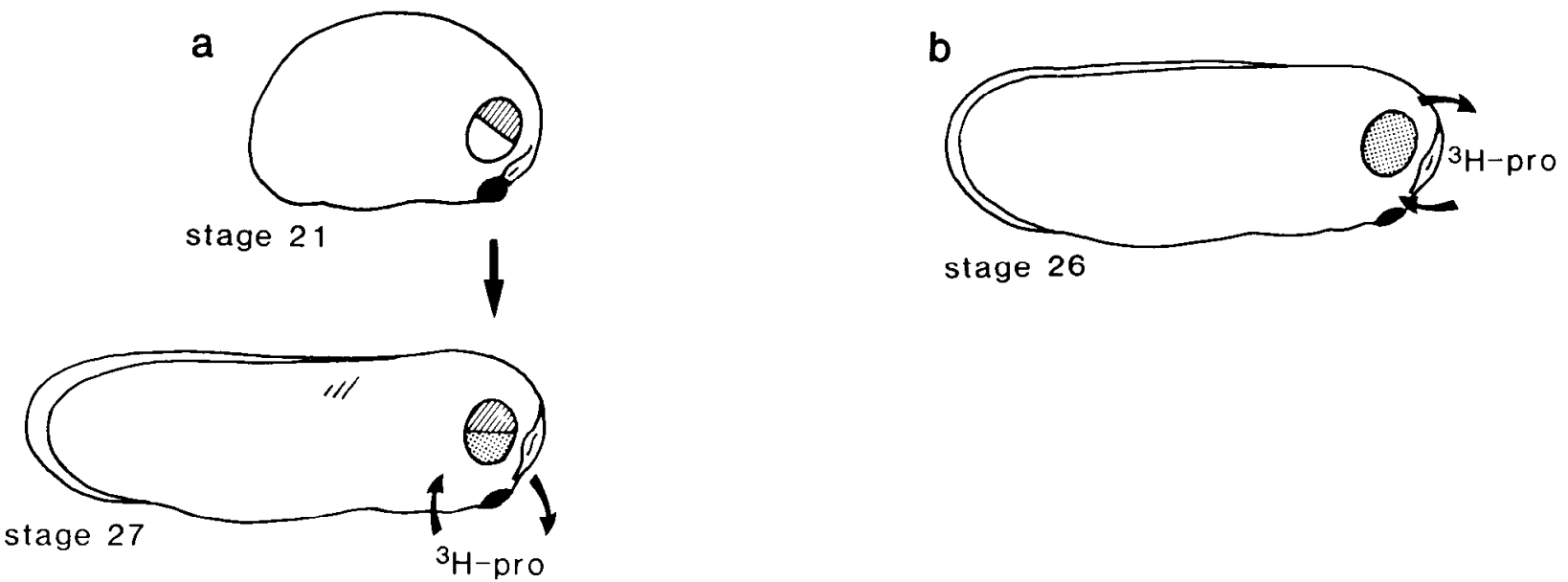

Figure 1. Diagram to illustrate the three lypes of experiments performed on embryonic eyes. Using $\left[{ }^{3} \mathrm{H}\right]$ proline incubation, in series I, dorsal $(a)$ and ventral $(b)$ sectors (one fourth to one third) were labeled; in series II, labeled dorsal halves of stage 21 eyes were grafted in place of stage 27 dorsal halves; and in series III, eyes were constructed with stage 21 dorsal halves and labeled ventral halves at stage $27(a)$, and whole eyes were labeled $(b)$. See the text for further details.

see Fig. 1), where dorsal retinal grafts were required to be developmentally behind the host eyes, donor embryos were raised at $14^{\circ} \mathrm{C}$ in a temperature-controlled incubator to retard their development while sibling host embryos were raised at room temperature.

\section{Method of [3]proline incubation}

The method of labeling growing retinal fibers by incubating presumptive eye tissue in $\left[{ }^{3} \mathrm{H}\right]$ proline has been described briefly in a previous report (Holt and Harris, 1983). Operations were performed in $66 \%$ Niu Twitty solution (Rugh, 1962) containing 2 times the normal concentrations of $\mathrm{Ca}^{2+}$ and $\mathrm{Mg}^{2+}$ to accelerate healing, and $0.2 \%$ gentamycin. The anesthetic, MS 222 (ethyl $m$ - aminobenzoate methanesulfonic acid; Aldrich), was added fresh to the operating solution at a concentration of $1: 10,000$. The $\mathrm{pH}$ of the operating and incubating media was optimal around $\mathrm{pH}$ 7.6.

Embryos at stages 21/22, 26, and 27 (staging according to the method of Nieuwkoop and Faber, 1956), before the onset of retinal ganglion cell axonogenesis, were positioned on their sides in wax beds in the operating dish and held in place with a piece of glass across their flank. Pieces of presumptive eye tissue were dissected out and transferred with a Spemann pipette to a $100-\mu \mathrm{l}$ drop of $66 \%$ Niu Twitty solution containing $100 \mu \mathrm{Ci} / \mathrm{ml}$ of $\left[{ }^{3} \mathrm{H}\right]$ proline (specific activity, $70 \mathrm{Ci} / \mathrm{mmol}$; Amersham). The incubation solution containcd $0.2 \%$ genta- 
mycin but no MS 222. Sectors of eye rudiments were incubated for 15 to $20 \mathrm{~min}$ and then taken through six changes of fresh $66 \%$ Niu Twitty solution in $0.2-\mathrm{ml}-$ capacity wells (approximately 5 min total wash). Incubated pieces were grafted back into the eye in their original positions and in the same orientation and held in place with a chip of glass until they healed (10 to 20 min). Differential pigmentation of the eye vesicle as well as the distinctive shape of dissected eye sectors aided in orienting the transplants correctly.

Approximately $30 \mathrm{~min}$ after the operations, embryos were transferred to $66 \%$ Niu Twitty solution in separate Petri dishes, and 12 to $24 \mathrm{hr}$ later this concentration was reduced to $10 \%$ for subsequent rearing.

\section{Types of transplant}

Three classes of experiments were performed. These are illustrated in Figure 1 and are divided into series I, II, and III. All operations were done at room temperature $\left(\sim 20^{\circ} \mathrm{C}\right)$, before axonal outgrowth from the retina.

Series I experiments were designed to follow the normal developmental schedule of nerve fibers growing from the dorsal and ventral extremes of the retina. At stage 26 , pieces of dorsal (series Ia) and ventral (series Ib) eye tissue comprising one-fourth to one-third of the eye primordium were labeled by $\left[{ }^{3} \mathrm{H}\right]$ proline incubation.

Optic axons have first been detected in the eye of Xenopus at stage 28 (Cima and Grant, 1980); they begin to arrive in the tectal rudiment at stage $37 / 38$ (see "Results"). Experimental animals were fixed from the beginning of axonal outgrowth to early stages of tectal innervation, stages 29 to 41 . A total of 177 animals were used in series I: 85 dorsals (series Ia) and 92 ventrals (series Ib).

The timing experiments in series II $(n=88)$ were done to delay the differentiation of the dorsal half of the retina. When the eye primordium first appeared at stage 21/22 (21 to $23 \mathrm{hr}$ postfertilization), dorsal halves were dissected out, labeled by $\left[{ }^{3} \mathrm{H}\right]$ proline incubation, and transplanted to host stage 27 ( $\sim 32 \mathrm{hr}$ postfertilization) eyes in place of their normal dorsal halves. Thus, transplanted dorsal eye tissue was at least $9 \mathrm{hr}$ behind the host. Larvae were fixed at each developmental stage from stage 32 to 42 , and the time course of delayed dorsal fibers was examined autoradiographically.

The two types of control experiments, illustrated in Figure 1 (series IIIla and IIIb), were as follows. To test whether stage 21 dorsal half transplants had retarded the development of the host ventral half in the series II experiments, young stage 21 dorsal halves were transplanted, unlabeled, to stage 27 hosts, and the ventral halves of these same eyes were labeled by incubation (see series IIIa in Fig. 1). Animals were fixed at each stage from $35 / 36$ to $41(n=31)$, and the time course of the ventral fibre outgrowth from these eyes was compared with that of normal ventral outgrowth in series Ib.

'The experiments in series IIIb comprised labeling whole eye primordia at stage $26(n=24)$ and were done to control for the possible retardation effects of dissecting out sectors of eye tissue in series I. Larvae were fixed from stages 32 to 41 , and the time course of outgrowth from the whole retina was compared with that from dorsal and ventral extremes in series I.

\section{Surgery}

Fine tungsten needles, sharpened electrolytically, or insect pins were used for dissecting eye primordia. In series I operations, an incision was made across the horizontal axis of the vesicle, as illustrated in Figure 1, and continued around either the dorsal or the ventral margin of the primordium. In the timing experiments in which stage 21 embryos were used, cyes were transected oblique to the horizontal meridian, as illustrated in Figure 1. This ensured that the presumptive dorsal retina, which lies nasodorsally in the early eye bud, was included in the transplant. Observations of early eye morphogenesis indicate that, as a result of new cells entering the eye vesicle in its nasoventral portion from the optic stalk, the carly primordium (stages 21 to 24 ) rotates so that cells which occupied nasal positions at stage 21 migrate to take up more dorsal positions by stage 25 (Holt, 1982). By stage 26, cells in the dorsal vesicle have reached their definitive locations, although migration continues from the optic stalk into the ventral eye rudiment until eye cup formation is complete at stage 32 (Holt, 1980). Because of this latter migration, care was taken to excise the entire optic stalk along with presumptive ventral retina during ventral eye surgery in series Ib, IIIa, and IIIlb.

\section{Histology}

Animals were fixed by immersion in $2.5 \%$ glutaraldehyde in $0.1 \mathrm{M}$ phosphate buffer at $\mathrm{pH}$ 7.4. After fixation for $1.5 \mathrm{hr}$ at $4^{\circ} \mathrm{C}$, they were dehydrated through a graded series of alcohols, cleared in cedar wood oil $(2 \mathrm{hr})$, and embedded in paraffin wax $\left(58^{\circ} \mathrm{C}\right.$ melting point). Brains were sectioned at 6 to $8 \mu \mathrm{m}$, mostly in the transverse plane. Parasagittal sections were cut for the studies on the optic tract. Serial sections were mounted on subbed slides and dewaxed in xylene.

For autoradiography, slides were dipped in $50 \%$ Kodak NTB-2 nuclear emulsion, dried, and stored in the dark at $4^{\circ} \mathrm{C}$. Following exposure times of 10 to 21 days, slides were developed for $3 \mathrm{~min}$ in Kodak D-19 at $20^{\circ} \mathrm{C}$, washed in $1 \%$ acetic acid, and fixed in Kodak fixer. After washing, slides were counterstained with Meyer's hematoxylin and eosin and coverslipped with Permount. Autoradiographs were examined under brightfield illumination in a Zeiss photomicroscope and drawings were made with the aid of a camera lucida attachment.

\section{Topographic analysis}

The tectal rudiment was identified as the area, caudal to the diencephalon, where the dorsal part of the midbrain and its lumen widen slightly and where the neuropil region expands in width (see, for example, Figs. 12 and 13). Longer survival periods after labeling have shown this area to differentiate mature tectal morphology (Holt, 1982).

Quantitation of the autoradiographic data for the extent and topography of tectal label was as follows. The dorsal junction on the pial surface between the central 

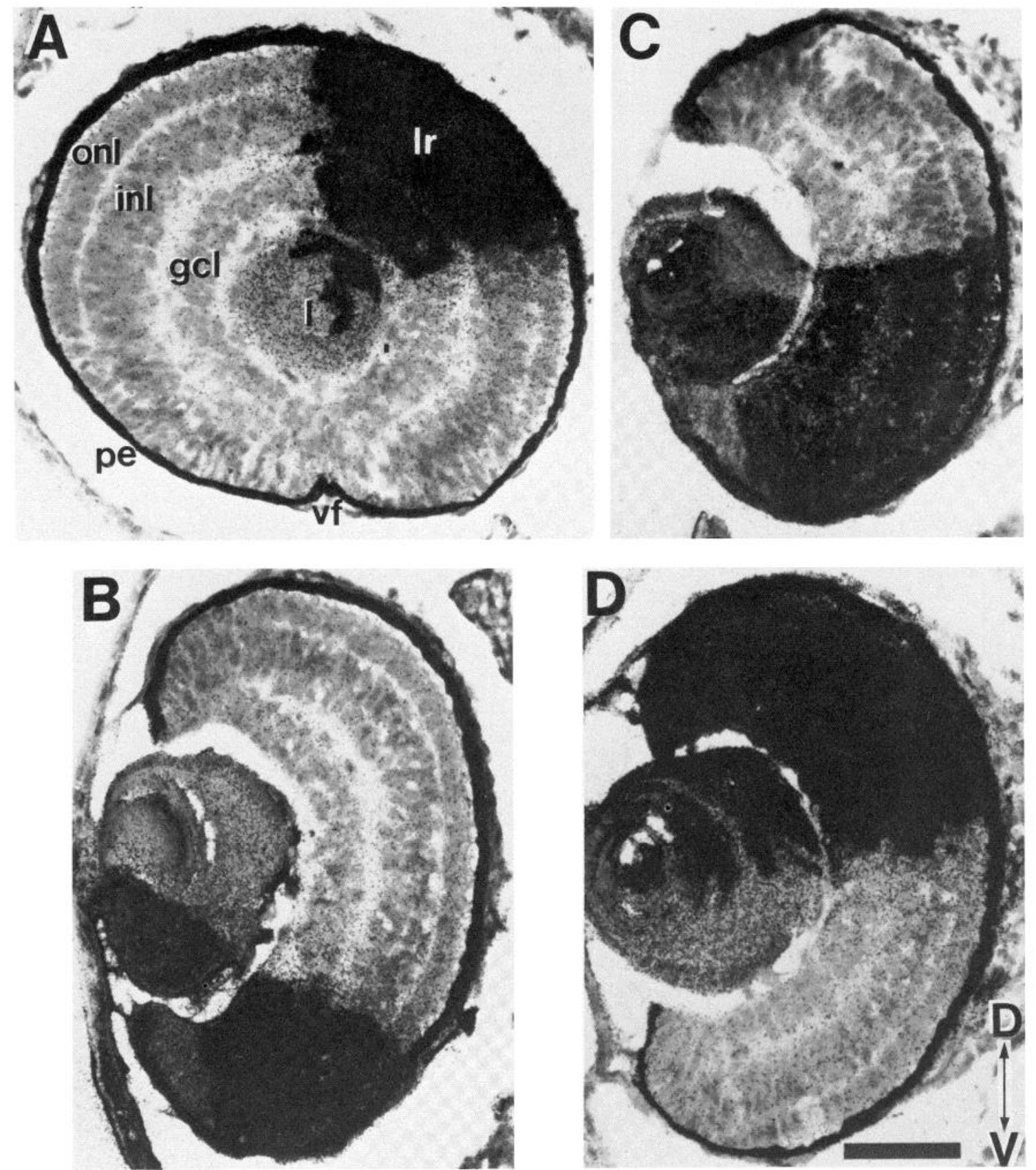

Figure 2. Autoradiographs of partially labeled eyes at stage 40 . A, Sagittal section of a series Ia eye showing dense label in the dorsonasal quadrant of the retina. The position of the ventral choroidal fissure $(v f)$ is indicated. Nasal is to the right, temporal to the left. $B$, Transverse section of an eye from series $\mathrm{Ib}$ showing label confined to the ventral third of the retina. $C$, Transverse section of a ventral control eye from series IIIa with a transplanted young dorsal half and a labeled ventral half. $D$, Transverse section from a series II eye showing label restricted to the transplanted (delayed) dorsal half of the retina. D, dorsal; $\mathrm{v}$, ventral; gcl, ganglion cell layer; inl, inner nuclear layer; $l r$, labeled retina; onl, outer nuclear layer; pe, pigment epithelium; $l$, lens. $S c a l e$ bar $=50 \mu \mathrm{m}$.

cell mass and the neuropil region of the tectum was taken as the origin (see Figs. 12 and 14) and a scale of micrometers was drawn along the pial surface. The dorsal and ventral boundaries of the tectal label were then measured with respect to the dorsal origin for each sample and the mean boundary positions were calculated for each class of experiment. No correction has been made for tissue shrinkage. This type of quantitation reduced errors of interpretation introduced by the small size of the tectal rudiment at the beginning of innervation $(100 \mu \mathrm{m}$ dor- soventrally), the lack of an obvious ventral tectal boundary due to the absence of landmarks (discrete cell layers do not begin to differentiate until stages 43 to 45 ), and variabilities in grain densities, exposure times, and brain sizes.

\section{Results \\ Eyes}

About $60 \%$ of operated eyes appeared normal, being of similar size to and morphologically indistinguishable 
from unoperated eyes. The other $40 \%$ showed signs of surgical trauma, such as disjunction between the labeled and unlabeled parts of the eye. These were mostly detected and discarded when the embryos were screened a few hours after the operation.

Autoradiographs of eyes from each experimental series are shown in Figure 2. The boundary between labeled and unlabeled cells was usually sharp, indicating that little leakage of $\left[{ }^{3} \mathrm{H}\right]$ proline had occurred from the incubated tissue. Labeled axons from dorsal ganglion cells can be seen traversing the optic fiber layer and entering the optic nerve head (Fig. $4 A$ ).

In eyes with grafted young dorsal halves, the normal early dorsal expression of pigmentation was usually retarded. Pigmentation is normally expressed in a graded fashion from dorsal to ventral choroid during early stage 30 s, so that the delay seen in dorsal pigmentation in the heterochronic eyes indicated the effectiveness of the heterochronic grafts. There was a tendency for label to spread more from retinal tissue incubated at early stages $(21 / 22)$ than later (26 and 27). Consequently, the nonincubated (ventral) parts of heterochronic eyes in series II tended to show slightly more label than did those of series I and IIIa (Fig. 2). However, the density of label in nonincubated retina was usually much less than in incubated regions, and in the majority of cases, this did not interfere with the specific tectal labeling patterns. Only in about $10 \%$ of the cases was the spread heavy enough to result in diffuse tectal labeling.

The migration of retinal pigment epithelial (PE) cells from dorsal to more ventral locations in the eye rudiment, previously observed with $\left[{ }^{3} \mathrm{H}\right]$ thymidine labeling (Holt, 1980), was particularly striking at stages 30 to 34 in eyes which had received stage 21 dorsal transplants (series II). This is shown in Figure 3, where labeled PE cells can be seen $100 \mu \mathrm{m}$ or more away from the labeled dorsal region of the retina. Presumptive pigment epithelium (PE) lies in the dorsal part of the optic vesicle (in the proximal wall) and the optic stalk. During differentiation, the PE cells, originally spherical in shape, flatten to form a monolayer migrating ventrally from their dorsal locations. The distance migrated by labeled PE cells was found to be much smaller ( $20 \mu \mathrm{m}$ at most) when the dorsal retinal sectors were labeled at later stages of development, as in series Ia (stage 26), indicating that the bulk of the movement of PE cells ventrally takes place between stages 21 and 26 . After stage $35 / 36$, the $\mathrm{PE}$ becomes too heavily pigmented to distinguish labeled cells.

Labeled PE cells were observed in close association with the optic nerve head, indicating that nascent axons probably come into contact with these dorsally derived PE cells when they first grow out of the eye. Miswiring defects in mammals are known to correlate with decreased retinal pigmentation (LaVail et al., 1978), and possibly this early association is important for axon guidance. This association probably would not have changed in the heterochronic eyes since the host dorsal halves were substituted at stage 27 , after the bulk of pigment migration had occurred, so that the positional ancestry of the delayed dorsal axons and that of the host $\mathrm{PE}$ cells they grew out next to was similar.

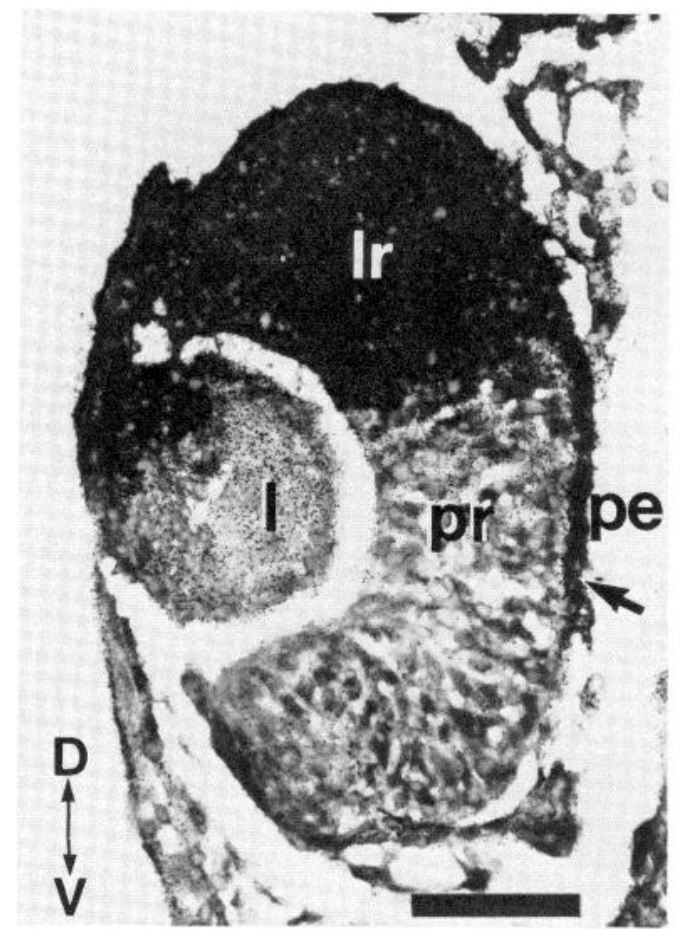

Figure 3. Autoradiograph of a stage 32 eye from series II showing the ventral migration of the pigment epithelium (pe). The arrow points to labeled pe cells situated ventral to the dorsal labeled retina $(l r)$. Retinal layers have not yet differentiated in this newly formed eye cup. The optic nerve head (not shown, but see Fig. 4) forms in close apposition to pe cells which have migrated from more dorsal locations. $p r$, presumptive retina. Conventions are as in Figure 2. Scale bar $=50 \mu \mathrm{m}$.

\section{Pathway ordering}

At stage 40 , the optic nerve head has approximately 1000 nerve fibers (Wilson, 1971) and is approximately $15 \mu \mathrm{m}$ in diameter. Retinotopic order could be detected at this level of the pathway in approximately $60 \%$ of the eyes in series Ia. The rest were either diffusely labeled or were uninterpretable due to inappropriate section plane. Examples of ordered optic nerve heads are shown in Figure 4, $A$ and $B$, where, in correspondence with retinal label, grains are restricted to the dorsal half. The optic nerve head lies in the ventral part of the early eye cup (see Fig. $4 A$ ), and its topography could not be reliably assessed in ventral labeled eyes (series Ib and IIIa) because of ambiguities introduced by label from abutting retinal cells.

The presence or absence of visible order in the optic nerve head seemed to depend on the total amount of retina labeled. When small pieces of retina (thirds or less) were labeled, grains were confined to the appropriate dorsal half (Fig. $4 B$ ), but after larger retinal sectors were labeled (halves or more), grains tended to be less localized. Given the small diameter of the optic nerve head $(15 \mu \mathrm{m})$, the latter cases could simply reflect the limits of resolution of the technique rather than a lack of retinotopicity. Alternatively, this spread might represent a population of dispersed (non-retinotopic) axons.

In the heterochronic group, only about $15 \%$ of the eyes showed evidence of retinotopic ordering in the optic 

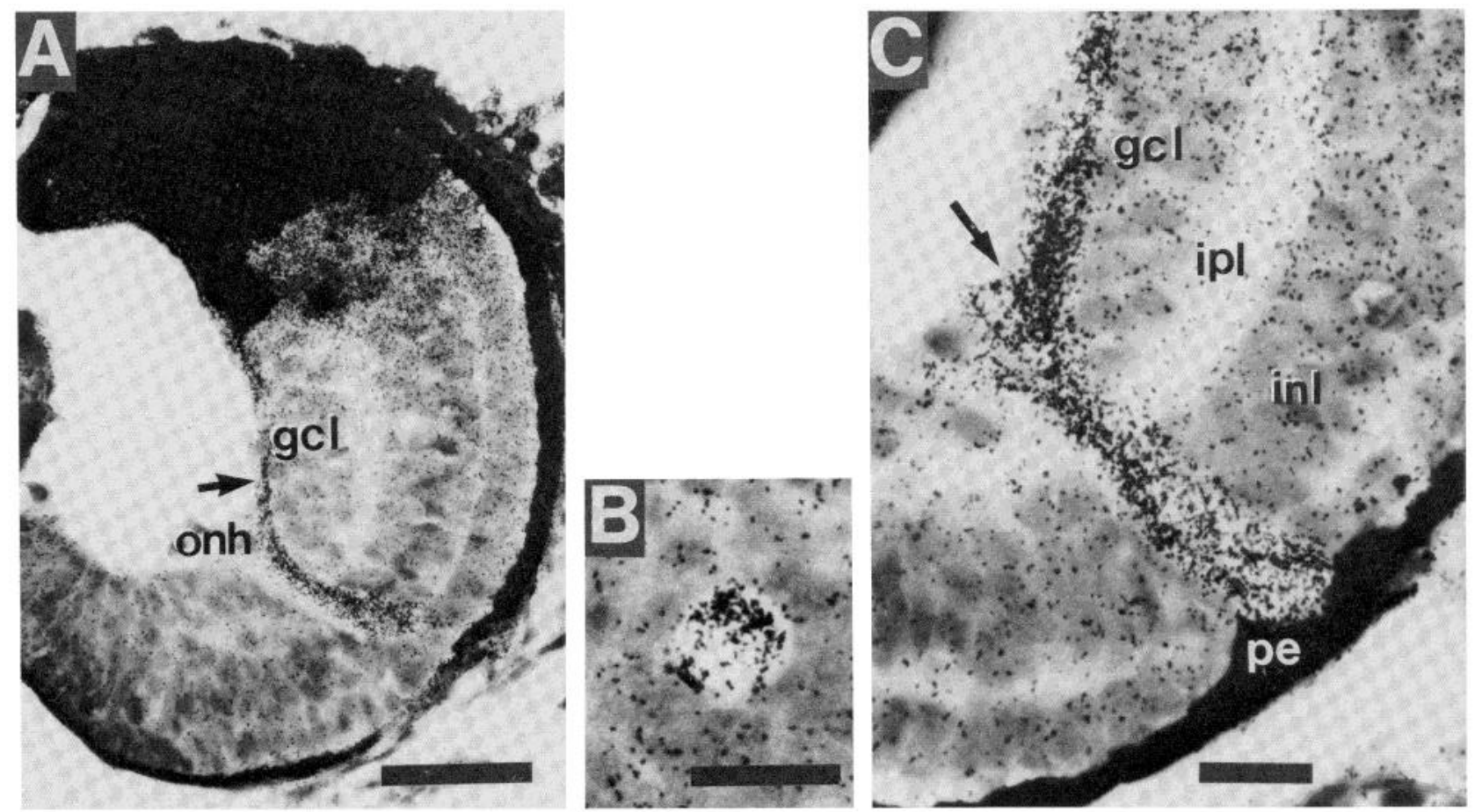

Figure 4. The optic nerve heads of normal and heterochronic eyes at stage 40. A, Transverse section of an eye from series Ia showing labeled cells in the dorsal retinal third and labeled optic axons in the optic fiber layer (arrow) and in the optic nerve head (onh); autoradiographic grains are positioned in the dorsal part of the onh in correspondence with the pattern of retinal label indicating that ganglion cell axons are retinotopically arranged in the onh. $B$ shows a transverse section of the onh belonging to the eye shown in Figure $2 A$ : the pattern of label parallels that of retinal label. By contrast, label is dispersed throughout the onh of the heterochronic eye in $C$ and appears to be concentrated more along the ventral border, suggesting that the late outgrowth of these dorsal fibers induced a reversal in fiber ordering at the onh. The arrow in $C$ indicates labeled axons entering the onh. ipl, inner plexiform layer. Conventions are as in Figure 2. Scale bars $=50 \mu \mathrm{m}(A)$; and $20 \mu \mathrm{m}(B$ and $C)$.

nerve head; the rest appeared to be disordered with grains being distributed evenly across the whole cross-section. Sometimes a reversal of the normal order could be detected (see Fig. $4 C$ ) where label was most dense along the ventral part of the nerve head. This increased disorder in the heterochronic group could be due to any of several factors: (1) a larger amount of presumptive retina labeled in the first place (half as compared with a third in series 1; see Fig. 1); (2) an increased spread of label from the incubated to nonincubated regions of the retina (see "Eyes"), or (3) disrupted time of arrival of axons at the nerve head due to delayed outgrowth from dorsal retina. The data do not permit these possibilities to be distinguished. However, the reversed patterns (see Fig. $4 C$ ) are consistent with the addition of nascent axons to the ventral part of the optic nerve head (Scholes, 1979; Bodick and Levinthal, 1980) and thus with alternative 3.

Order, when present in the nerve head, could usually be traced into the proximal optic nerve but could not be detected distally close to the chiasm. This is consistent with Fawcett's (1981) observations in the adult Xenopus optic nerve where ordering is tight close to the eye but becomes less so toward the chiasm.

Fibers course dorsocaudally in the optic tract along the lateral edge of the diencephalon (see Fig. 13), and the parasagittal sections of the optic tract of series I brains (Fig. 5) indicate that dorsal retinal fibers tend to occupy more ventral and caudal positions, whereas ventral fibers run close to the boundary between the diencephalon and the telencephalon in a more dorsal and rostral position. This agrees with previous observations made at older ages (Fawcett and Gaze, 1982; Holt, 1982). Of the four brains cut in this plane from heterochronic series II, two showed projections traveling in the appropriate ventral part of the tract and the other two appeared to be spread throughout the tract. Thus, it is unclear whether the altered times of outgrowth have disrupted fiber order in the optic tract.

These results indicate that, during normal development, the optic nerve head, the proximal optic nerve, and the optic tract are topographically ordered $a b$ initio. The precision of this ordering could not be determined nor could it be decided whether the heterochronic pathway is normal or disrupted (for reasons discussed above). There was some indication, however, that the altered temporal relations had disrupted, and at the optic nerve head possibly reversed, the spatial ordering of the pathway.

\section{Time course of retinal fiber outgrowth}

The data obtained from stage 32 to 40 brains from each series of experiments are plotted in the histograms shown in Figure 6, and the time courses of retinal fiber growth along the optic pathway to the tectum are summarized in Table I and Figure 11. 

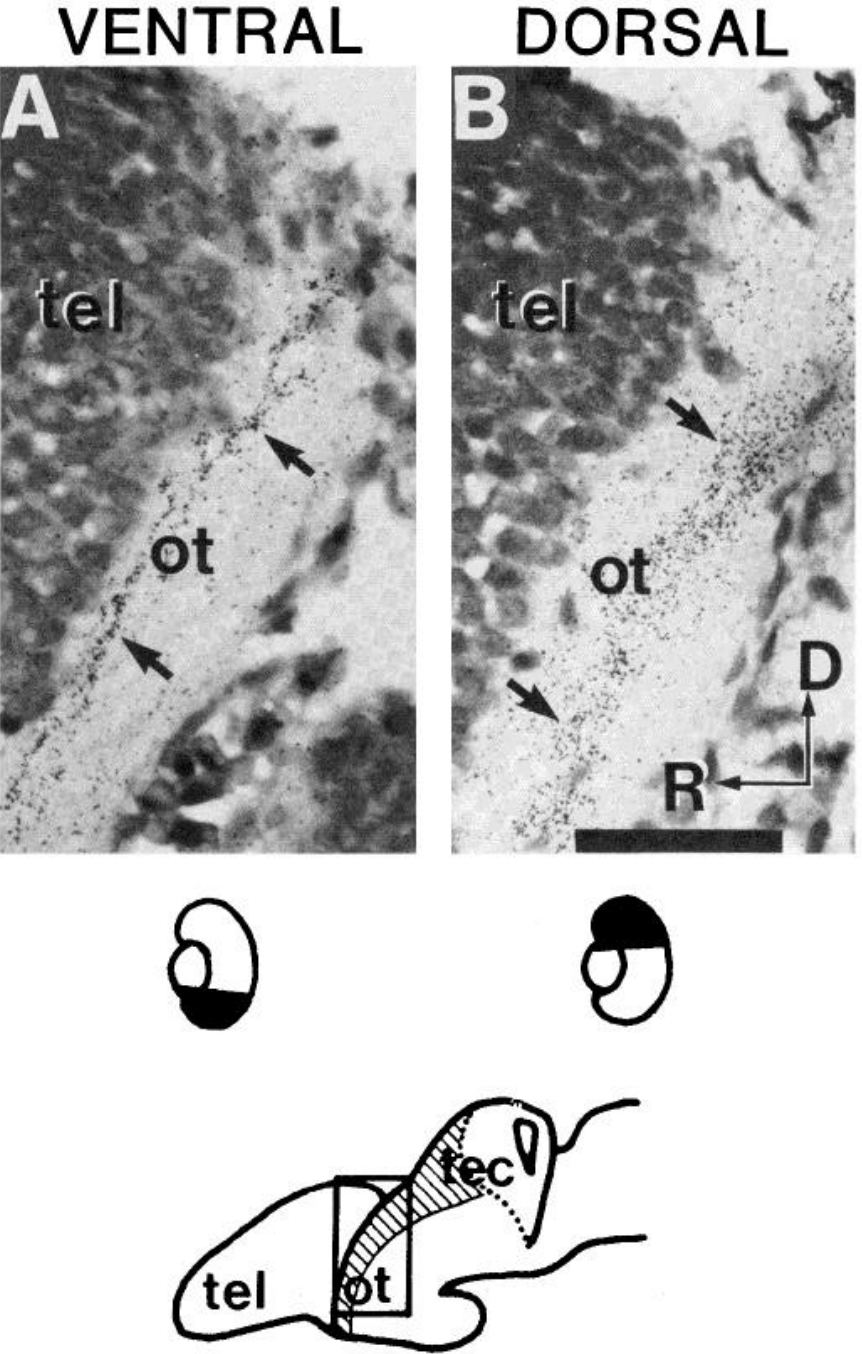

Figure 5. Order in the optic tract at stage 40 shown in parasagittal section from series I experiments. The frame drawn in the brain outline (bottom) indicates the area of optic tract (ot) shown in the photomicrographs; the retinal origins of the labeled tract fibers in $A$ and $B$ are indicated (black areas) in the eyes outlined (bottom). A shows labeled fibers from ventral retina (series $\mathrm{Ib}$ ) running dorsorostrally in the optic tract along the rostral edge of the presumptive diencephalon close to the border between the diencephalic neuropil and the gray matter of the telencephalon (tel). $B$ shows labeled fibers from dorsal retina (series Ia) located in the ventrocaudal part of the tract. This tract organization matches the spatial order of initial tectal innervation. $D$, dorsal; $R$, rostral. Conventions are as in Figure 2. Scale bar $=50 \mu \mathrm{m}$.

\section{Series I: Dorsal versus ventral outgrowth}

Labeled axons of dorsal origin (series Ia) were first detected in the temporal half of the retinal rudiment at stage 28 , indicating that the first ganglion cells to differentiate axons are those in dorsotemporal retina. Through stages 28 and $29 / 30$, they grow ventrally in the temporal part of the retina toward the ventral choroidal fissure. They leave the eye through the fissure's apex, forming the primitive optic nerve head, and grow along the ventrotemporal edge of the optic stalk. At stages 30 and 31, labeled dorsal fibers are evident in the optic stalk. This structure joins the eye primordium to the presumptive diencephalon, providing a direct substrate bridge for the pioneer fibers to grow on to reach the chiasm. Dorsal fibers first arrive at the chiasm around stage 32 (Fig. $7 A$ ). Grant et al. (1980) have observed a similar time course of outgrowth from the retina with silver staining. Around stage $33 / 34$, dorsal retinal fibers reach the ventral diencephalon (Fig. $7 B$ ), and from there they grow dorsocaudally along the rostral and lateral surface of the presumptive diencephalon and reach the mid-to-dorsal diencephalon at stage $35 / 36$ (Fig. $8 A$ ). They approach the tectal rudiment from a rostral and ventral position and arrive in its ventral part at stage $37 / 38$ (Fig. 9A), approximately $19 \mathrm{hr}$ after leaving the eye. This initial population of axons is calculated to grow at a rate of approximately $40 \mu \mathrm{m} / \mathrm{hr}$. The time of arrival of the first retinal axons in the tectal rudiment at stage $37 / 38$ is about $3 \mathrm{hr}$ earlier than previously reported (Gaze et al., 1974; Grant et al., 1980; Holt and Harris, 1983).

Ventral retinal fibers leave the eye about $6 \mathrm{hr}$ behind dorsal ones, around stage 33/34 (Fig. $7 \mathrm{C}$ ), and maintain a similar time lag throughout their course along the pathway to the tectum (see Table I). They reach the ventral diencephalon around stage $35 / 36$ (Fig. $8 B$ ), grow dorsally in the optic tract through stages $37 / 38$ and 39 (see Fig. $9 B$ and $10 B$ ), and arrive in the dorsal part of the tectal rudiment at stage 40 (Fig. $12 \mathrm{C}$ ) in a position slightly further caudal to the dorsal retinal terminals. Thus, ventral fibers begin to innervate the tectum after fibers from the dorsal retina (stage $37 / 38$ versus stage 40). The 12 -hr window between stages 39 and 40 made it impossible to define exactly when ventral fibers reach the tectum, but by extrapolating from the data on their time courses of growth along the pathway (see Table I), this must be about $6 \mathrm{hr}$ after dorsal fibers.

These data show that the dorsal retinal fibers pioneer the retinotectal pathway. These fibers are at least $6 \mathrm{hr}$ ahead of ventral fibers at each stage of development from leaving the eye cup, growing along the pathway, to innervating the tectum.

The reconstructions presented in Figure 13 depict the pathway taken by labeled dorsal and ventral fibers from

TABLE I

Times of arrival in hours postfertilization of retinal axons at different points along the pathway to the tectum

The times were taken from normal tables of Xenopus development (Nieuwkoop and Faber, 1956).

\begin{tabular}{lcccc}
\hline \multicolumn{1}{c}{$\begin{array}{c}\text { Part of Retina } \\
\text { Labeled }\end{array}$} & Chiasm & $\begin{array}{c}\text { Ventral } \\
\text { Dien- } \\
\text { cephalon }\end{array}$ & $\begin{array}{c}\text { Mid- } \\
\text { Dien- } \\
\text { cephalon }\end{array}$ & $\begin{array}{c}\text { Dorsal } \\
\text { Dien- } \\
\text { cephalon }\end{array}$ \\
\hline $\begin{array}{l}\text { Dorsal } \\
\text { (Series Ia) }\end{array}$ & 40 & 44 & 47 & 50 \\
$\begin{array}{l}\text { Ventral } \\
\text { (Series Ib) }\end{array}$ & 46 & 50 & 53 & 56 \\
$\begin{array}{l}\text { Delayed Dorsal } \\
\text { (Series II) }\end{array}$ & 50 & 53 & $56+$ & $60+$ \\
$\begin{array}{l}\text { Ventral (C) } \\
\text { (Series IIIa) }\end{array}$ & 46 & 50 & 53 & 56 \\
$\begin{array}{l}\text { Whole (C) } \\
\text { (Series IIIb) }\end{array}$ & 40 & 44 & 47 & 50 \\
\hline
\end{tabular}

a “(C)" indicates control experiments. 

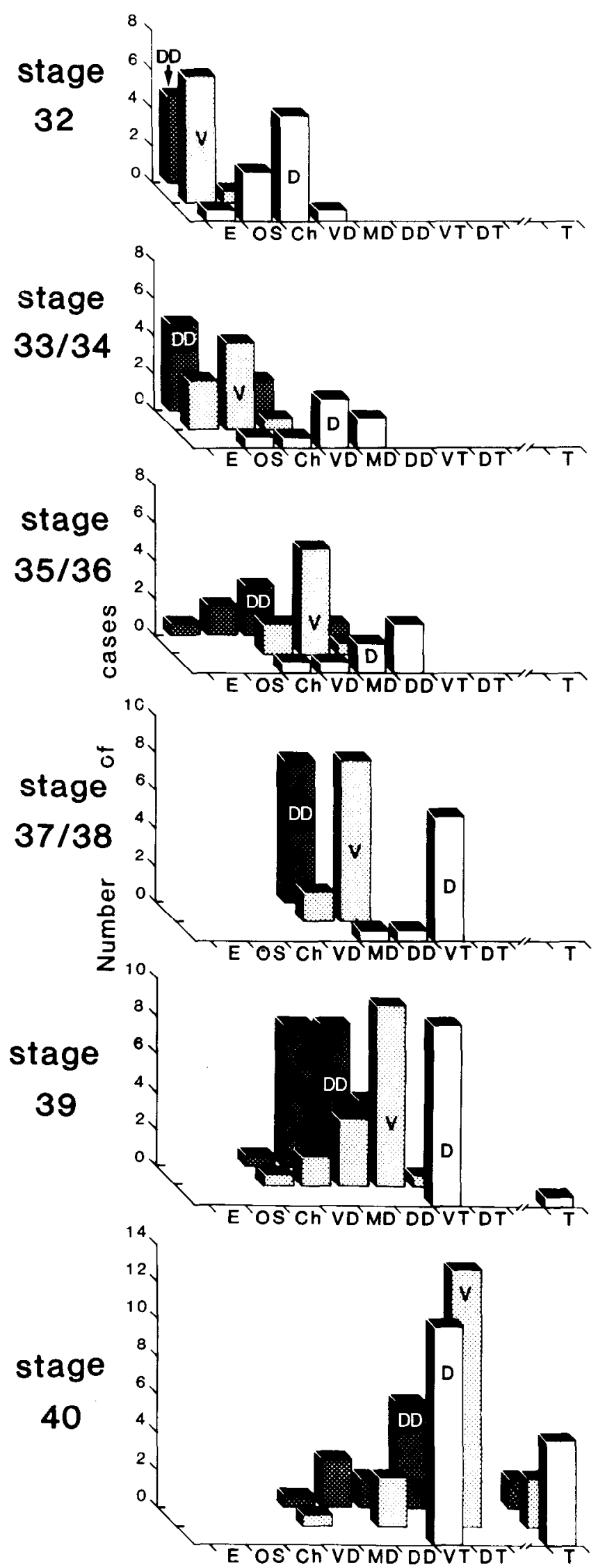
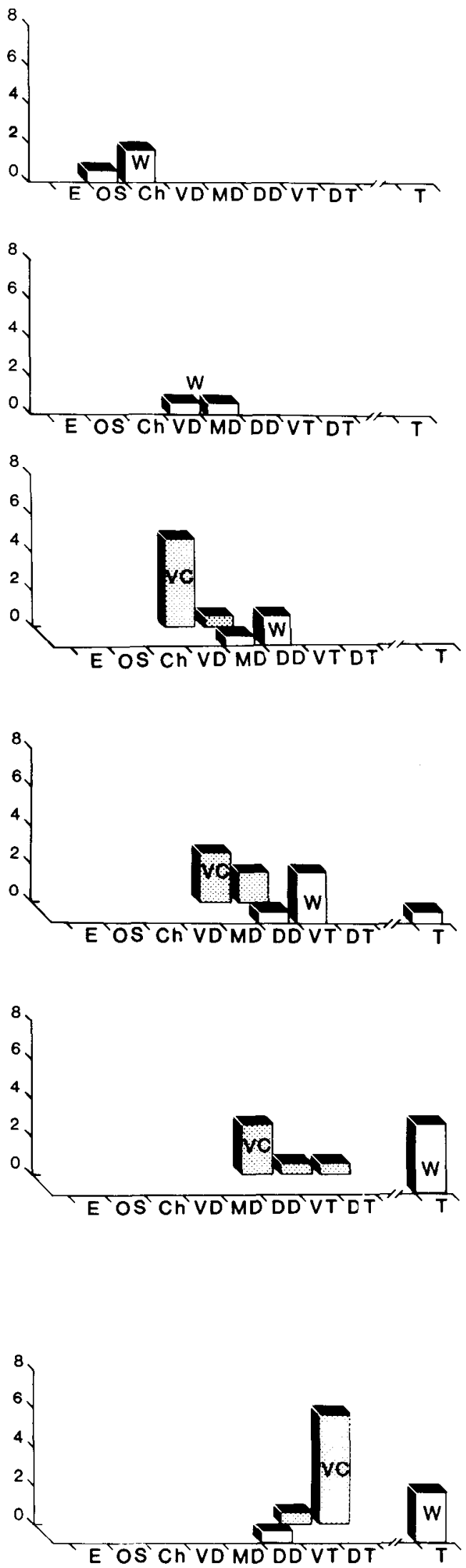

Position in pathway arid tectum

Figure 6. Histograms showing the data obtained from experiments in series I, II, and III from stages 32 to 40 . The most medial point reached by fibers growing along the pathway are plotted as well as the areas (dorsal and ventral) of tectal label. Spread projections are denoted as whole tectal label $(T)$. $D$, dorsal fibers (series Ia); $V$, ventral fibers (series IIb); $D D$, delayed dorsal fibers (series II); VC, ventral control projections (series IIIa); $W$, whole eye projections (series IIIb). The positions in the pathway are: $E$, eye; $O S$, optic stalk; $C h$, chiasm; $V D$, ventral diencephalon; $M D$, mid-diencephalon; $D D$, dorsal diencephalon; and in the tectum; VT, ventral tectum; $D T$, dorsal tectum; $T$, entire tectum. 


\section{DORSAL}

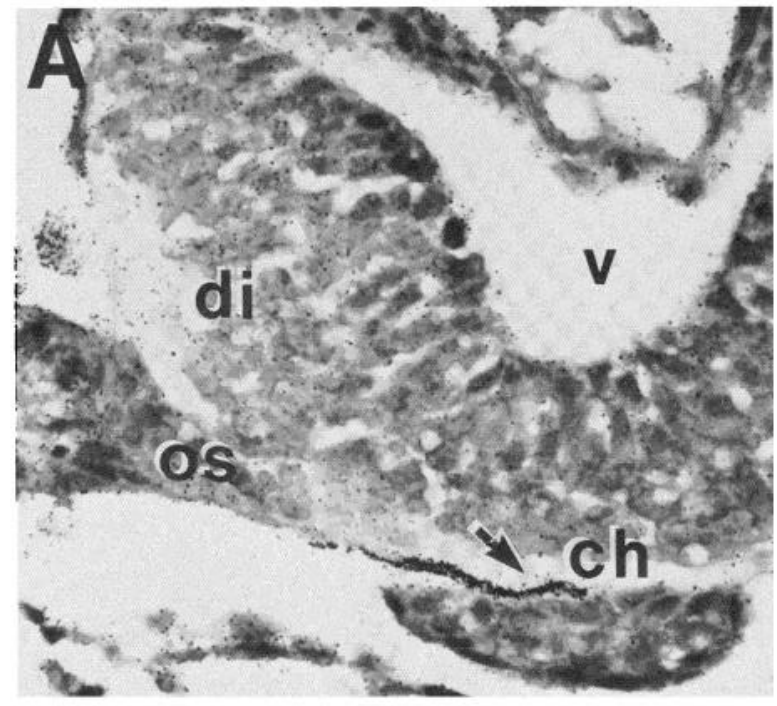

stage 32

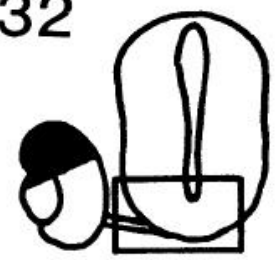

VENTRAL
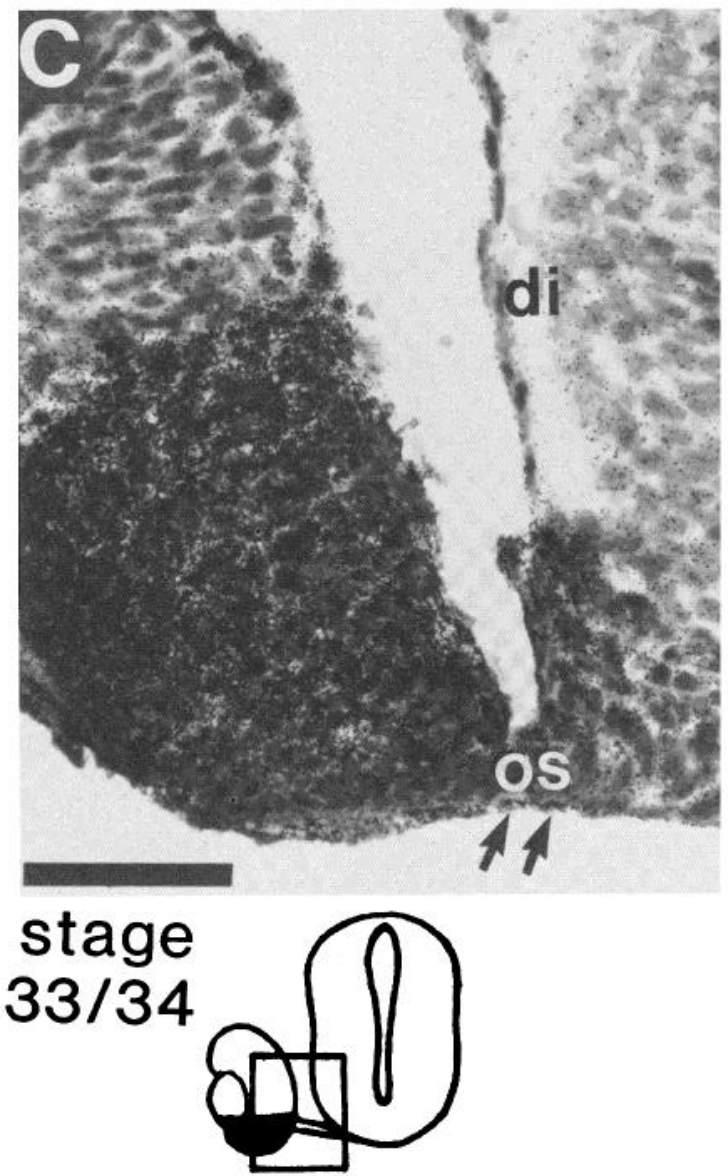

DORSAL

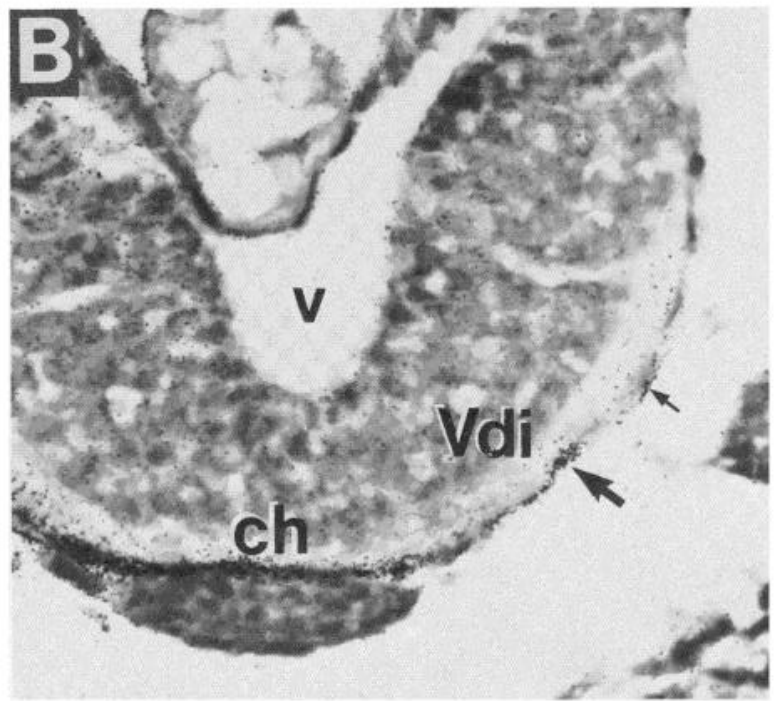

\section{stage $33 / 34$}

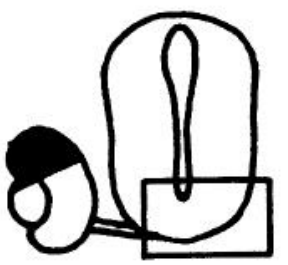

Figure 7. Pioneer dorsal retinal fibers at early stages in the optic pathway ( $A$ and $B$ ) and later growing ventral fibers $(C)$. The frames in the transverse brain outlines (bottom) demarcate the area included in the photomicrographs above. The part of the retina labeled in each case is indicated in the eye outlines (black area, bottom). A, Labeled dorsal fibers (arrow) from series Ia arriving at the chiasm $(\mathrm{ch})$ at stage 32 . $B$, By stage $33 / 34$, dorsal fibers have reached the ventral diencephalon (Vdi; large arrow). The small arrow indicates a single line of grains, possibly a single pioneer axon growing ahead of the others. $C$ shows labeled fibers from ventral retina (series Ib) entering the optic stalk (os; arrows). A more or less continuous line of grains distinguishes labeled fibers from surrounding labeled optic stalk and retinal cells. di, diencephalon; $v$, ventricle of the midbrain. Dorsal is up, ventral is down. Scale bar $=50 \mu \mathrm{m}$. 
DORSAL
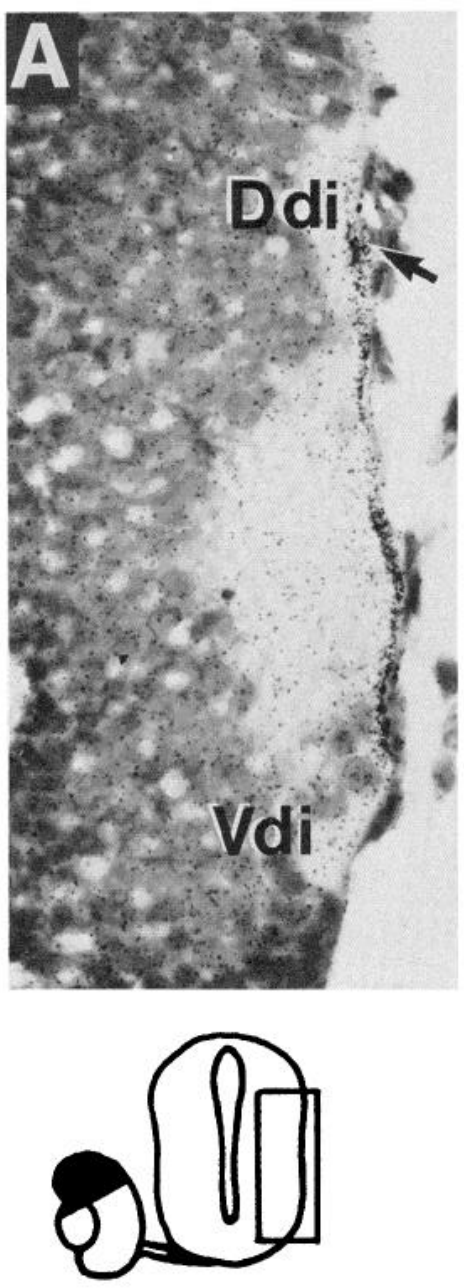

VENTRAL
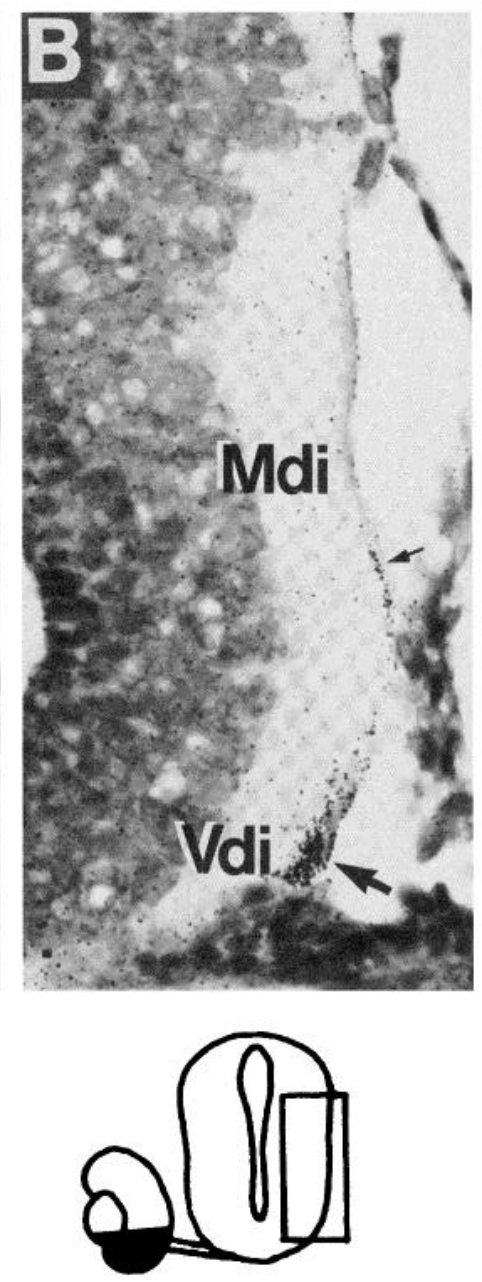

DELAYED DORSAL
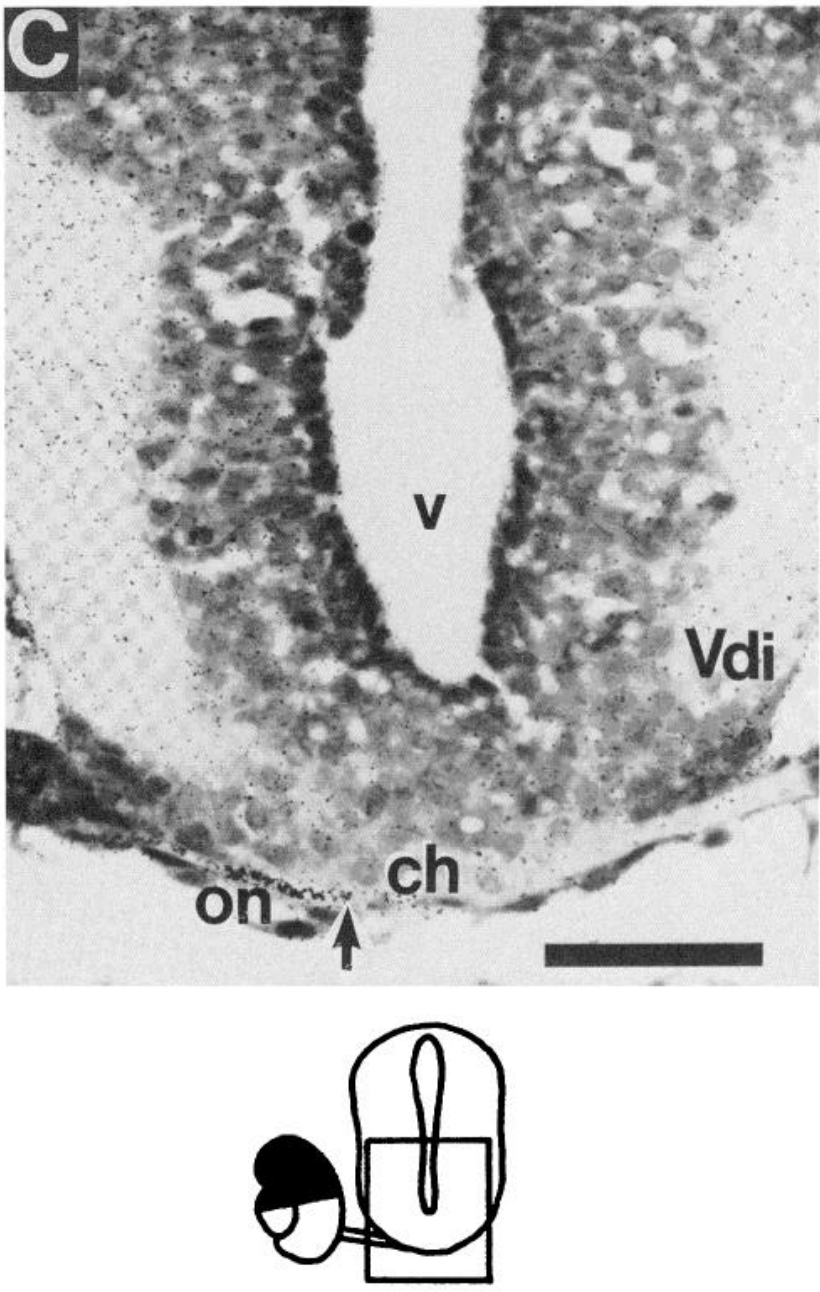

\section{stage $35 / 36$}

Figure 8. Positions of dorsal $(A)$, ventral $(B)$, and delayed dorsal $(C)$ retinal axons in the optic pathway at stage $35 / 36$. $A$ shows axons from dorsal retina (series Ia) coursing up the diencephalic wall close to the pial surface and reaching its most dorsal part (arrow; $D d i$, dorsal diencephalon). B, Labeled axons from ventral retina (series $\mathrm{Ib}$ ) in the ventral diecephalon (Vdi; large arrow). The small arrow indicates a single line of grains in mid-diencephalon ( $M d i)$, possibly a single axon. $C$, Axons from delayed retinal ganglion cells (series II) growing into the chiasm $(\mathrm{ch})$. Note the comparatively advanced age of the brain with respect to that in Figure $7 \mathrm{~A}$ when dorsal axons normally reach the chiasm. (i.e., more extensive diencephalic neuropil and larger optic nerves (on)). Conventions are as in Figure 7. Scale bar $=50 \mu \mathrm{m}$.

the chiasm to the tectum. The dense, narrow streak of label along the diencephalic wall (see Figs. 7 to 10) indicates that retinal axons cluster together as they grow to the tectum. Densities of label outside the main optic tract were not observed, indicating that axons do not randomly search out their pathway to the tectum. In contrast, pioneering axons growing to the basal optic nucleus (BON) were spread widely through the neuropil of the accessory optic tract (data not shown). This might reflect differences in the behavior of axons which grow through a matrix of neuropil to reach their target structure (BON) as compared with those that grow along the surface of the presumptive diencephalon close to the pia to reach the tectum.

\section{Series II: Delayed dorsal fiber outgrowth}

Series I experiments showed that dorsal retinal fibers arrive in the tectum first. A simple way of building the initial map, then, is for these fibers to connect with the first piece of tectum they encounter (ventral), causing later growing fibers to terminate further dorsally, the first sites being occupied and therefore unavailable. This simple hypothesis is now tested by delaying the time of dorsal retinal outgrowth with heterochronically grafted dorsal retinal halves as illustrated in Figure 1.

The data obtained from these series II experiments, up to stage 40 , are plotted in the histograms shown in Figure 6, and the positions of the delayed dorsal fibers 
DORSAL
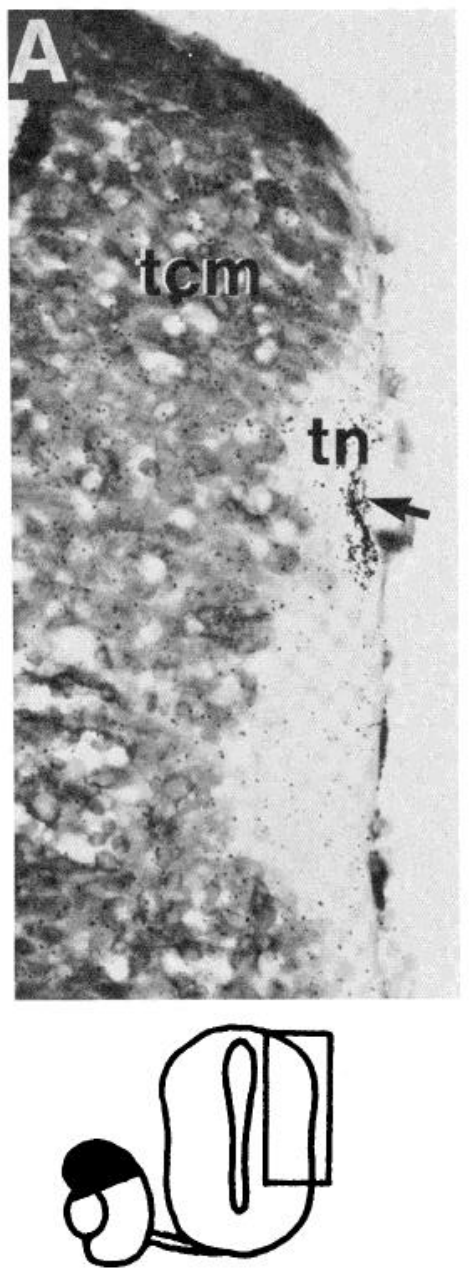

VENTRAL
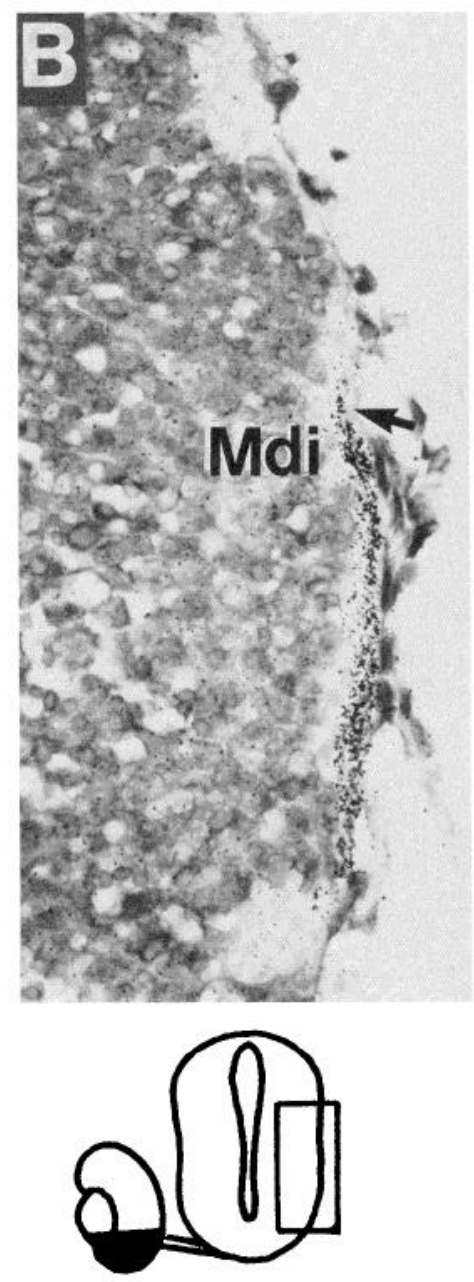

\section{DELAYED DORSAL}
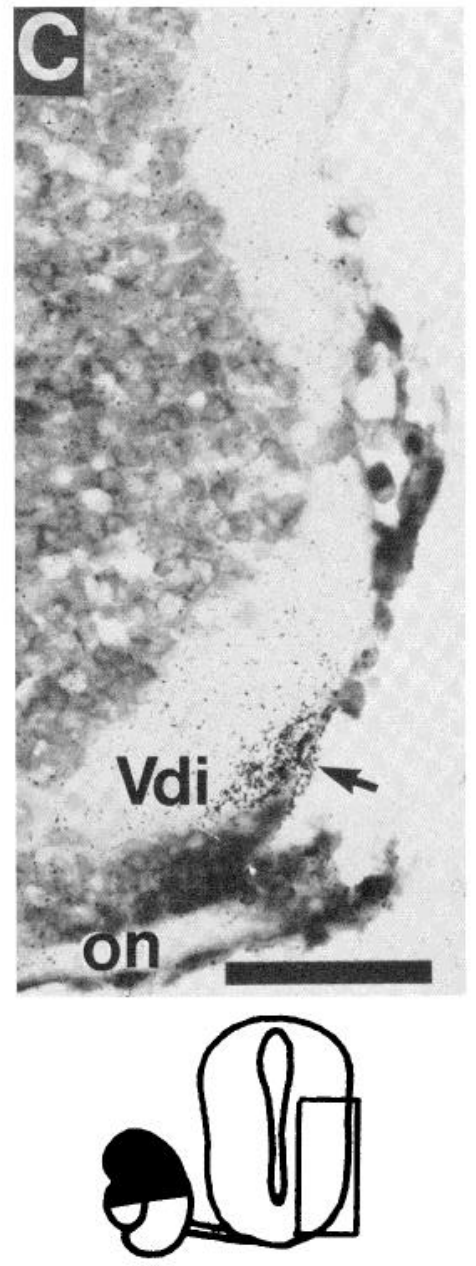

\section{stage $37 / 38$}

Figure 9. Positions of dorsal $(A)$, ventral $(B)$, and delayed dorsal $(C)$ retinal axons in the optic tract and tectum at stage $37 /$ 38. $A$, Dorsal retinal fibers (series Ia) accumulating in the ventral part of the tectal neuropil ( $t n$ ). B, Ventral retinal fibers (series $\mathrm{Ib}$ ) coursing up the edge of the diencephalon to the mid-diencephalon ( $M d i)$. $C$, Delayed dorsal fibers (series II) in the ventral diencephalon (Vdi). Arrows indicate the extreme medial positions of axons in $A, B$, and $C$. tcm, central cell mass of the tectal rudiment; on, optic nerve. Conventions are as in Figure 7. Scale bar $=50 \mu \mathrm{m}$.

at different stages of development are indicated in the summary diagram in Figure 11.

The delayed dorsal axons first reach the chiasm around stage $35 / 36$ (Fig. $8 C$ ), $9 \mathrm{hr}$ or more behind normal dorsal fibers (see Table I and Fig. 6). By this stage, most ventral fibers have reached the ventral diencephalon (Fig. $8 B$ ) and dorsal fibers from normal eyes are in the dorsal diencephalon (Fig. 8A). By stage $37 / 38$, most of the delayed axons are in the ventral diencephalon (compare with the dorsal locations of ventral and dorsal fibers in Fig. 9), $9 \mathrm{hr}$ behind normal dorsal fibers and at least 3 hr behind ventral fibers (Table I). At stage 39 , the delayed dorsal axons are situated in the ventral-to-mid diecephalon (Fig. $10 \mathrm{C}$ ), with a few in the dorsal dience- phalon. By stage $40,12 \mathrm{hr}$ after dorsal fibers normally arrive, labeled axons in just half of the cases have reached the tectum (see Fig. 6), and these were mostly confined to the ventral half (see Fig. 12 and 14). The rest ( $n=$ 16) arrived some $12 \mathrm{hr}$ later, between stages 40 and 41.

These results demonstrate that when stage $21 / 22$ dorsal halves are transplanted to stage 27 hosts, the retinal fibers enter the pathway and innervate the tectum 9 to $20 \mathrm{hr}$ later than normal. At all stages of development examined, their growth along the pathway was at least 3 $\mathrm{hr}$ behind the ventral fibers (see Table I), indicating that the latter population arrived in the tectum first and that the normal dorsal-to-ventral sequence of innervation had been reversed. 
DORSAL
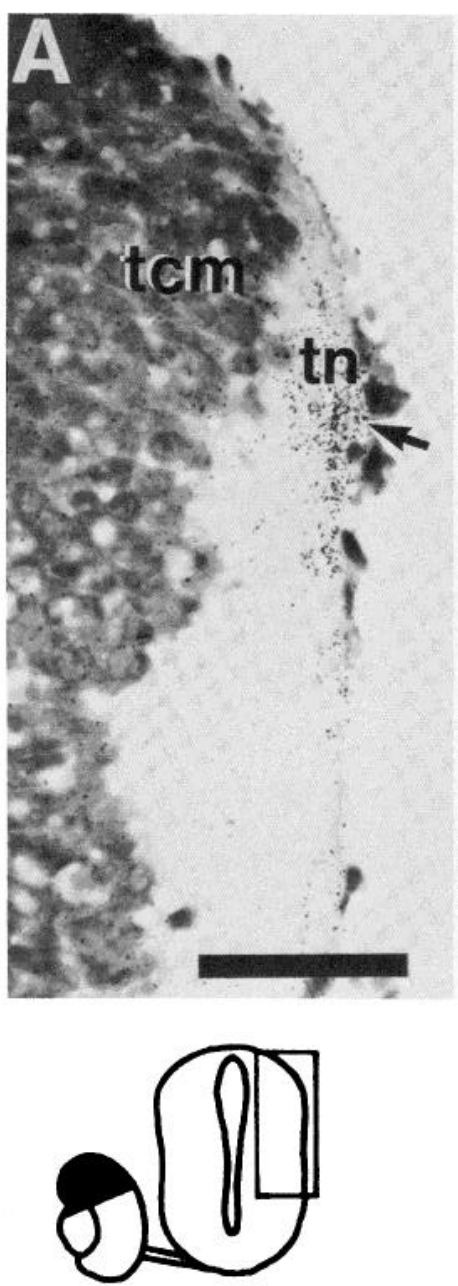

VENTRAL
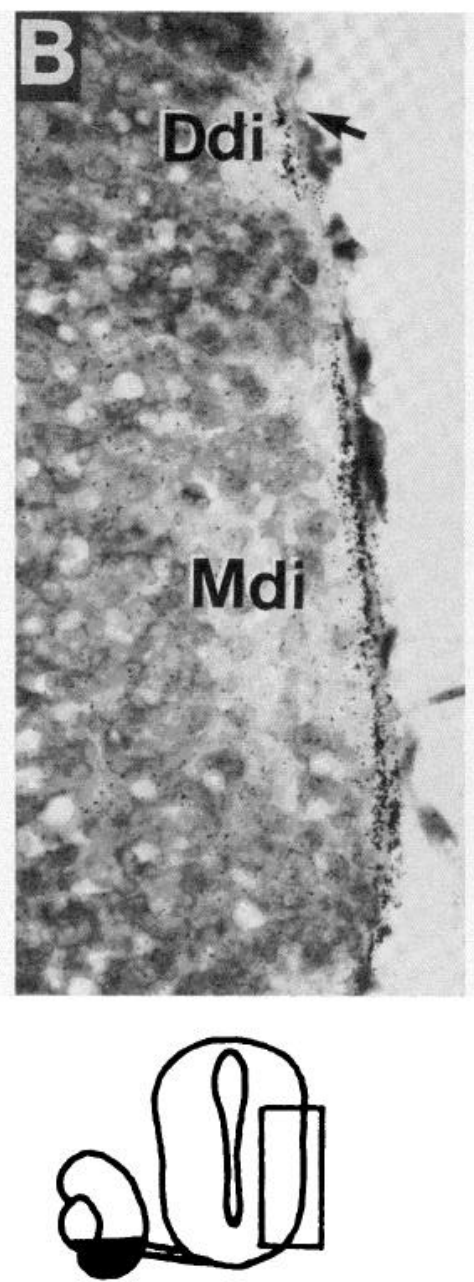

stage 39

\section{DELAYED DORSAL}
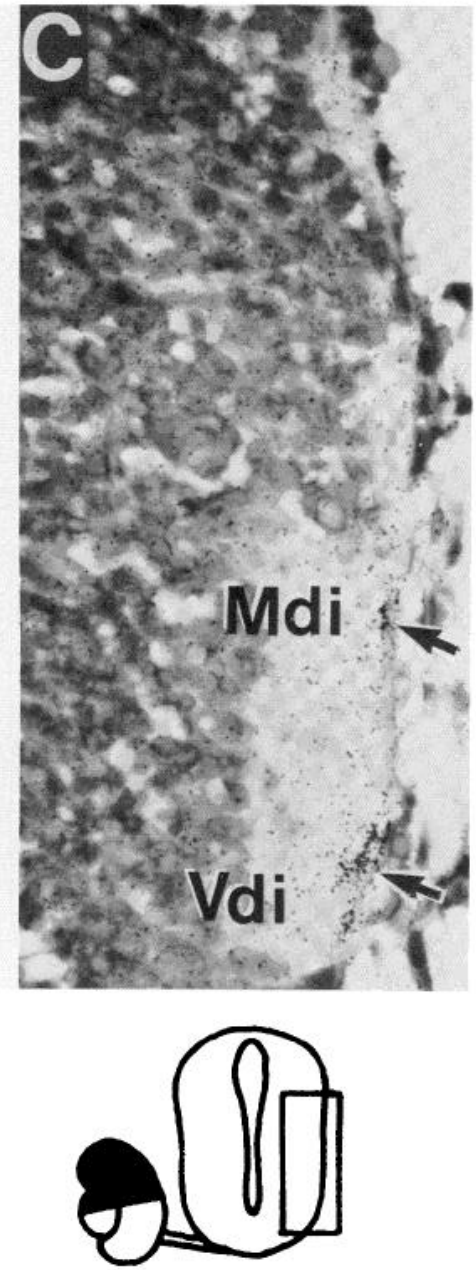

Figure 10. Positions of dorsal $(A)$, ventral $(B)$, and delayed dorsal $(C)$ retinal axons in the optic tract and tectum at stage 39 . $A$, Dorsal fibers (series Ia) accumulate in ventral tectal neuropil $(t n)$. $B$, Ventral fibers (series Ib) course along the lateral edge of the diencephalon and reach the dorsal diencephalon ( $D d i)$. C, Delayed dorsal fibers (series II) are in the ventral (Vdi) to middiencephalon (Mdi). Arrows indicate the extreme medial locations of labeled axons. Conventions are as in Figure 9. Scale bar = $50 \mu \mathrm{m}$.

\section{Series III: Control experiments}

Two sets of control experiments were run to control for (1) possible retardation effects due to the excision of small pieces of tissue from the eye primordium (series $\mathrm{IIIb}$, whole eye incubation) and (2) retarded outgrowth from the ventral retina which the young transplanted dorsal retinal tissue might induce (series IIIa, eyes with young dorsal grafts plus labeled ventral retinas). These latter series of experiments also served to test whether the population of ventral "follower" fibers could find their proper targets in the absence of the pioneering population of dorsal retinal fibers. The data obtained from these two sets of controls are shown in the histograms (Fig. 6), and the positions of these whole eye and ventral control fibers are included in the summary diagrams in Figure 11.
The results from the whole eye group show that fibers from the whole retina follow the same developmental schedule as dorsal retinal fibers (Table I; cf. $W$ and $D$ in the histograms in Fig. 6). Labeled fibers from the whole retina reach the chiasm at stage 32 , grow up the diencephalic wall from stages $33 / 34$ to $35 / 36$, and arrive in the ventral tectum at stage $37 / 38$. The entire dorsoventral extent of the tectal neuropil was labeled at stages 39,40 , and 41 (Figs. $12 E$ and 13). The label in the dorsal tectum at stage 39 , which was not found with dorsal retinal projections and occurs before the arrival of ventral fibers, might reflect the arrival of central retinal fibers since fibers of central origins were not labeled in the series I experiments. Because the time courses of outgrowth of the whole and dorsal retinal projections are the same, it may be concluded that the schedule of fiber outgrowth from incubated retinal fragments is not retarded. A fur- 
stage 32

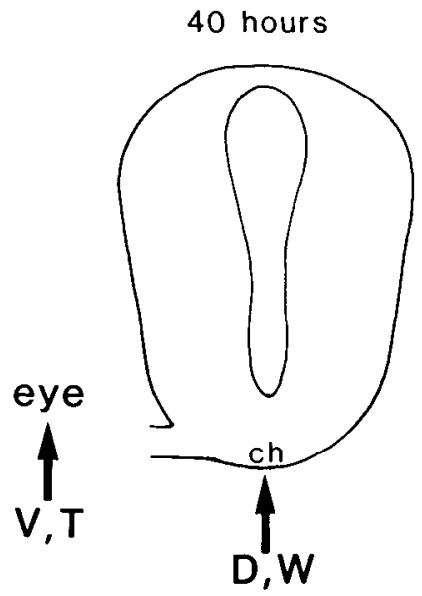

stage $37 / 38$

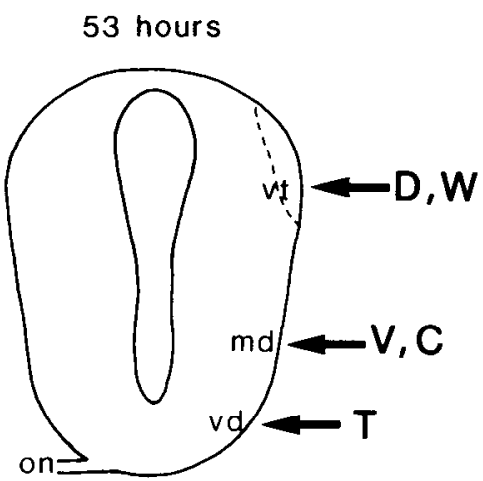

stage $33 / 34$

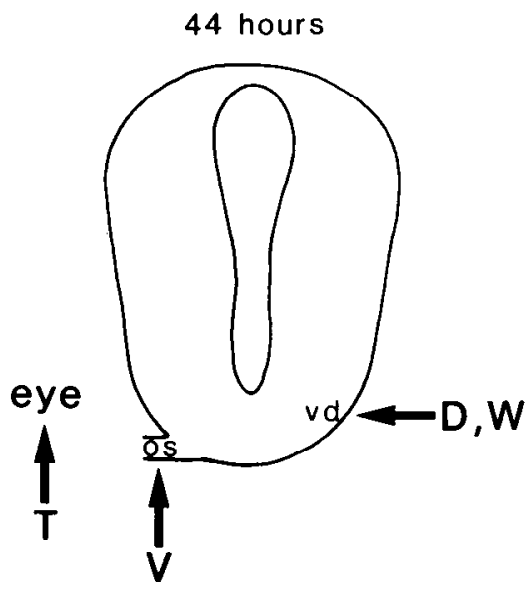

stage 39

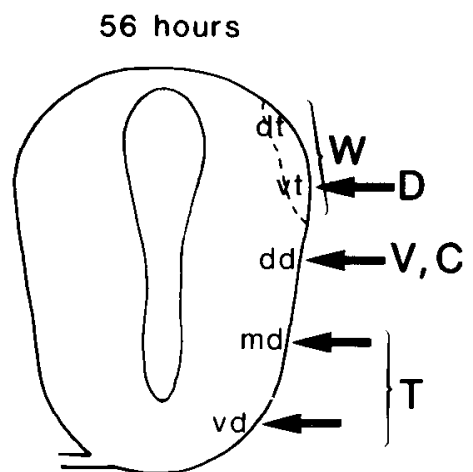

stage $35 / 36$

50 hours

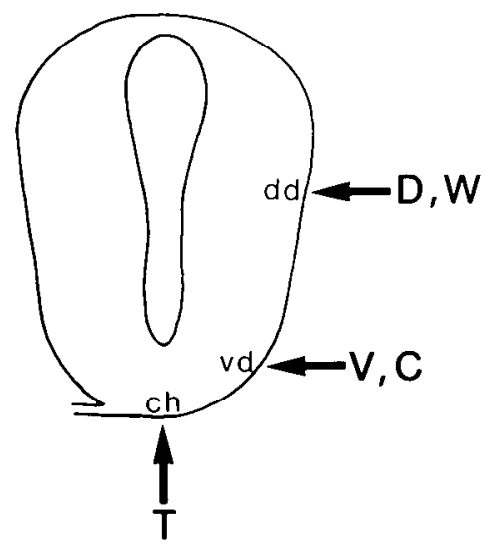

stage 40

66 hours

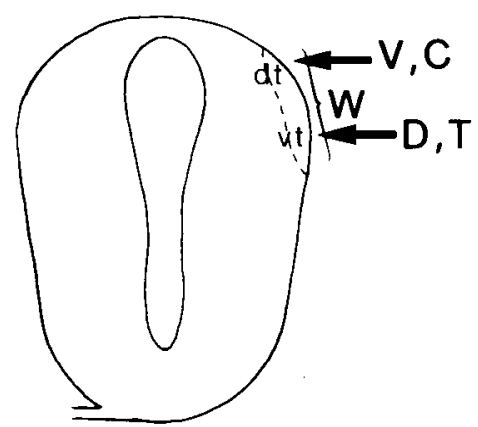

D dorsal

$V$ ventral

$\mathrm{T}$ delayed dorsal

W whole

C ventral control

Figure 11. Summary diagram to illustrate the developmental time courses of retinal axon outgrowth from each type of experimental eye. The number of hours postfertilization (at $20^{\circ} \mathrm{C}$, from Nieuwkoop and Faber, 1956) is given under the stage number. $D$, dorsal fibers (series Ia); $V$, venlral fibers (series Ib); $T$, delayed dorsal fibers (timing experiments, series II); $C$, ventral controls (series IIIa); $W$, whole eyes (series IIIb). ch, chiasm; $d d$, dorsal diencephalon; $d t$, dorsal tectum; md, mid-diencephalon; on, optic nerve; os, optic stalk; vd, ventral diencephalon; $v t$, ventral tectum.

ther indication that the schedule of outgrowth was normal from incubated sectors was that both the dorsal and the whole eye projections showed a time course of early growth similar to that described by Grant et al. (1980) from the unoperated early eye rudiment.

The ventral control eyes (series IIIa) showed a time course of fiber outgrowth similar to that of the ventral projections in series $\mathrm{Ib}$ (see Table I; cf. $V$ and $V C$ in Fig. $6)$. By stage $35 / 36$, the first stage examined in these experiments, fibers have reached the ventral diencephalon (see Fig. 6). Through stages $37 / 38$ and 39 , ventral fibers grow from mid- to dorsal diencephalon and enter the dorsal tectum by stage 40 (Fig. 12D). Despite arriving in the tectum before the pioneering fibers from the dorsal retina, ventral fibers go directly to their appropriate area of the tectum. These results demonstrate two things: (1) that delayed dorsal eye grafts do not retard the development of the rest of the eye, from which we can conclude the schedule of ventral retinal differentiation is autonomous, and (2) that the ventral fibers, normally the "followers," can find their targets in the absence of the pioneering population of dorsal retinal fibers.

\section{Topography of the projections}

The entire extent of the early retinotectal projection at stages 40 and 41 is shown in Figures $12 E$ and 13 . It measures approxiamtely $100 \mu \mathrm{m}$ dorsoventrally and about $25 \mu \mathrm{m}$ in depth (pial to the ventricular surface). The majority of the partially labeled projections (series I, II, and IIIa) were confined to their appropriate places 

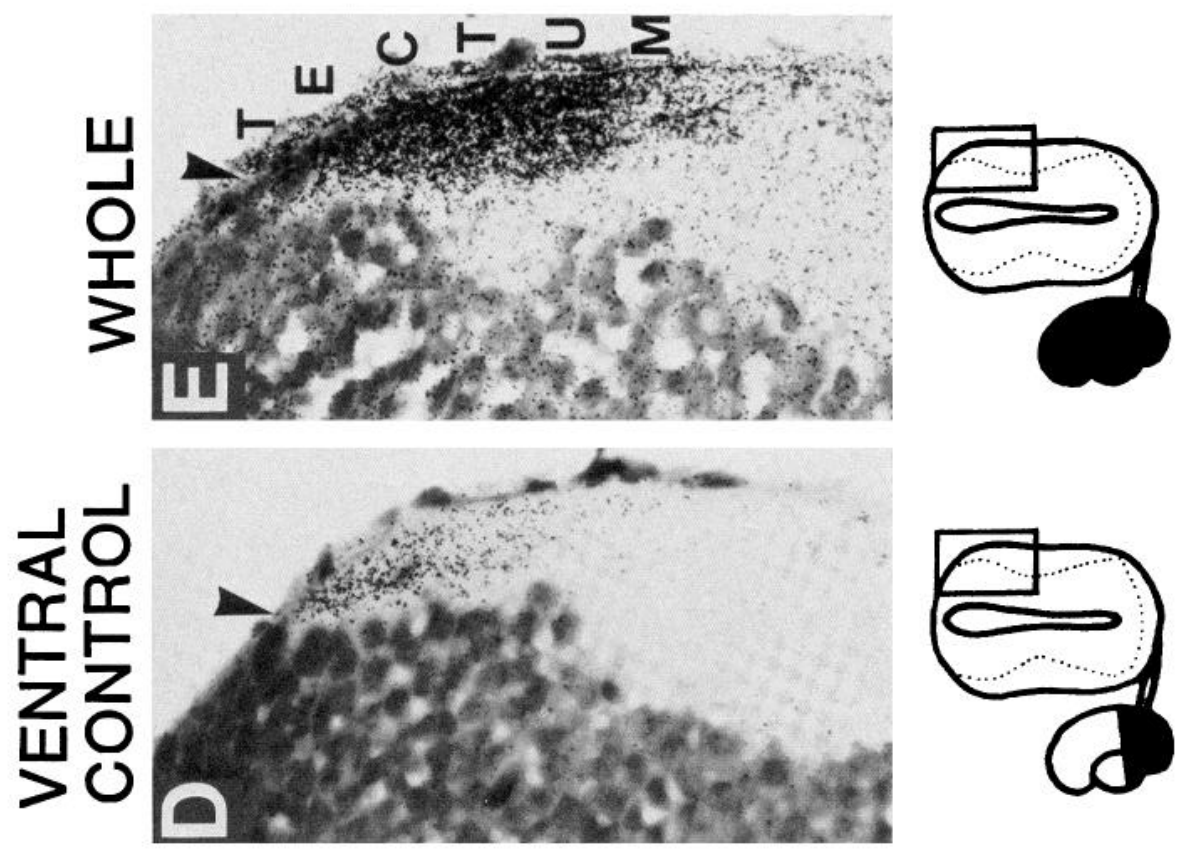

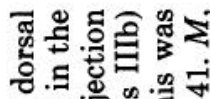
형. की 난 है 局

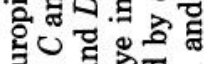
要

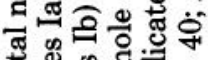

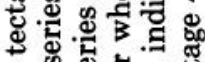
递兽的 政 .

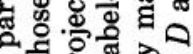
돈 政政 \&

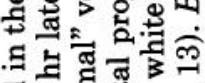
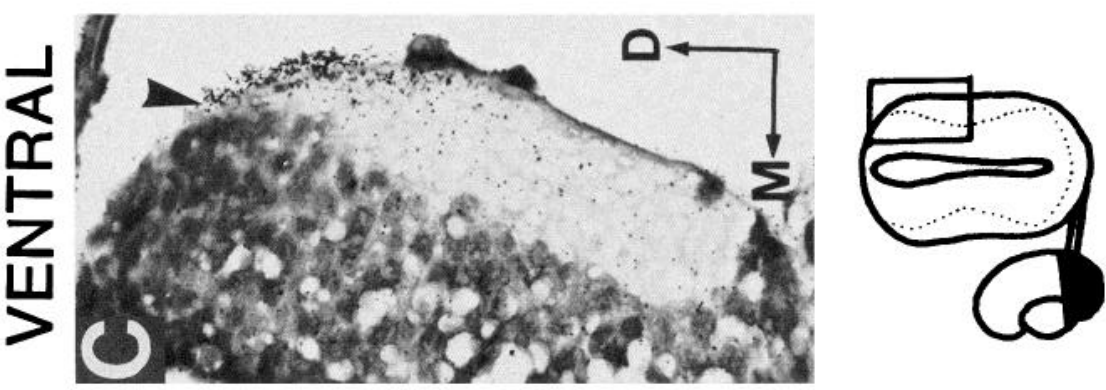

- ब

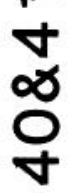

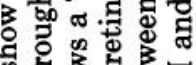

की

a

政

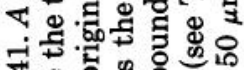

( ) F

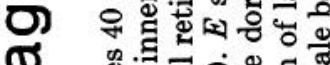

+ు
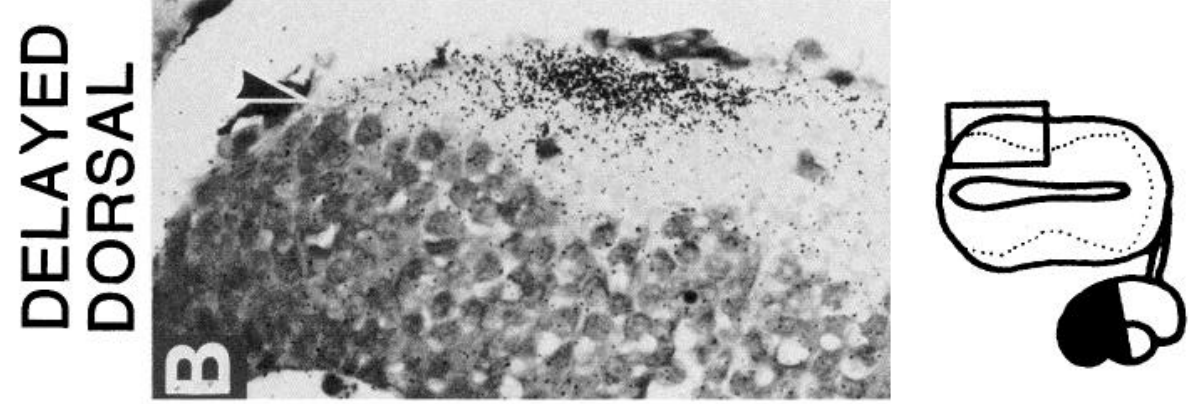

के के

政

要

要:

象.

政

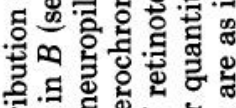
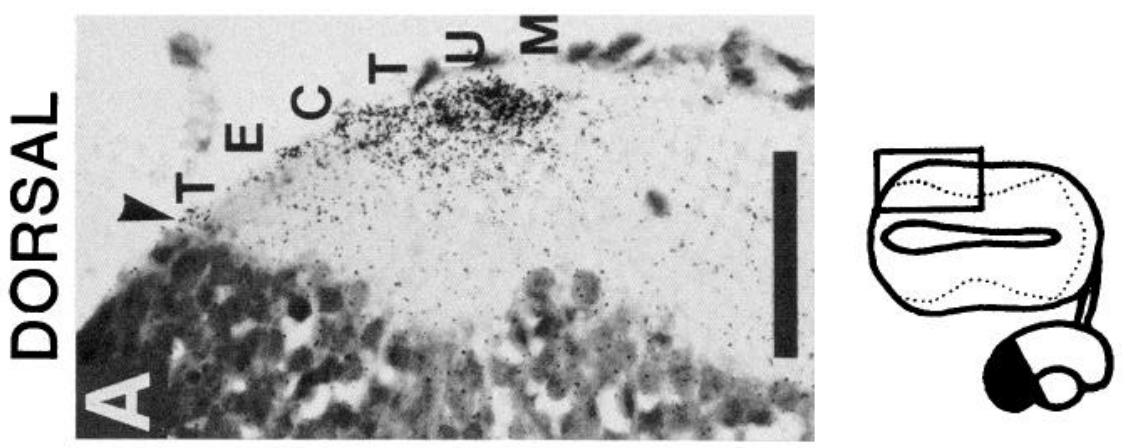

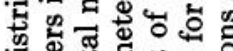

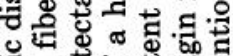

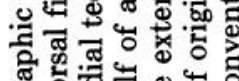

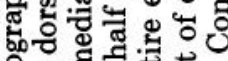

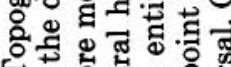

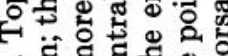

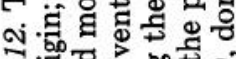

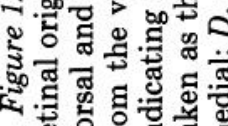

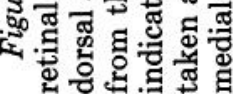



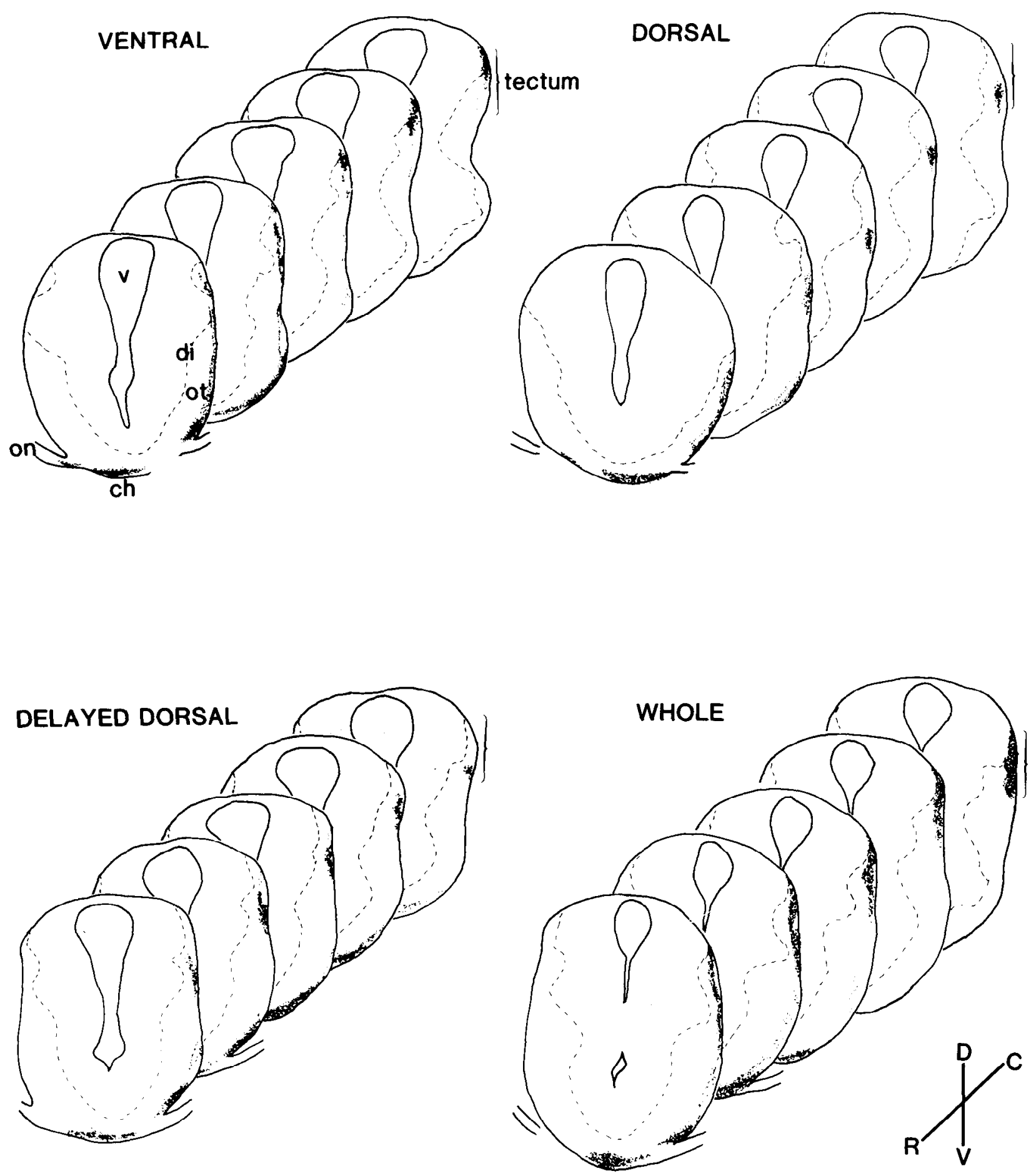

$100 \mu \mathrm{m}$

Figure 13. Reconstructions of autoradiographs of stage 40 midbrains showing partial and whole labeled retinal projections. Transverse sections at $6-\mu \mathrm{m}$ intervals are shown. The black dots represent the position of autoradiographic grains. Rostral sections in each reconstruction show the point of optic nerve entry (on), the chiasm (ch), and the optic tract (ot). More caudal sections show the tectum, the dorsoventral extent of which is indicated by a bracket on the most caudal one. Dashed lines indicate the boundary between the white and gray matter (the central gray extends from the ventricle $(v)$ to the dashed line). The dorsal part of the tectum becomes labeled after ventral and whole eye incubations and remains relatively free of label after dorsal eye incubations (compare the position of label with the position of the dorsal junction between white and gray matter), even when dorsal fibers are induced to arrive late. $d i$, diencephalon; $D$, dorsal; $V$, ventral; $R$, rostral; $C$, caudal. 
in either the dorsal or the ventral half of the tectal neuropil. The mean extents and the distribution of tectal labeling are presented in Table II and illustrated in Figure 14. In a minority of cases, label was spread across the entire dorsoventral extent (see $T$ in Fig. 6).

From a total of 40 cases in which dorsal fibers had reached the tectum in series Ia experiments (from stages $37 / 38$ to 41$), 29(72.5 \%)$ showed label restricted to the

TABLE II

Mean ( $\pm S D$ ) distances (micrometers) of the dorsal and ventral boundaries of the labeled part of the tectum after partial retinal labeling plus the average tectal coverage

These measurements are from stages 40 and 41 for the dorsal, ventral, and ventral control projections and from stages 40 to 42 for the delayed dorsal projections. These data are represented diagrammatically in Figure 14.

\begin{tabular}{lccc}
\hline \multicolumn{1}{c}{$\begin{array}{c}\text { Part of Retina } \\
\text { Labeled }\end{array}$} & $\begin{array}{c}\text { Dorsal Border } \\
\text { of Tectal Label }\end{array}$ & $\begin{array}{c}\text { Ventral Border } \\
\text { of Tectal Label }\end{array}$ & $\begin{array}{c}\text { Mean Tec- } \\
\text { tal } \\
\text { Coverage }\end{array}$ \\
\hline $\begin{array}{l}\text { Dorsal Third } \\
(n=19)\end{array}$ & $53 \pm 12$ & $95 \pm 19$ & 42 \\
$\begin{array}{l}\text { (Series Ia) } \\
\text { Ventral Third } \\
(n=18)\end{array}$ & $7 \pm 9$ & $52 \pm 11$ & 45 \\
$\begin{array}{l}\text { (Series Ib) } \\
\text { Delayed Dorsal Half } \\
(n=19)\end{array}$ & $45 \pm 13$ & $93 \pm 17$ & 48 \\
$\begin{array}{l}\text { (Series II) } \\
\text { Ventral Half Control } \\
(n=11)\end{array}$ & $11 \pm 10$ & $66 \pm 17$ & \\
\begin{tabular}{l} 
(Series IIIa) \\
\hline
\end{tabular} & & & \\
\hline
\end{tabular}

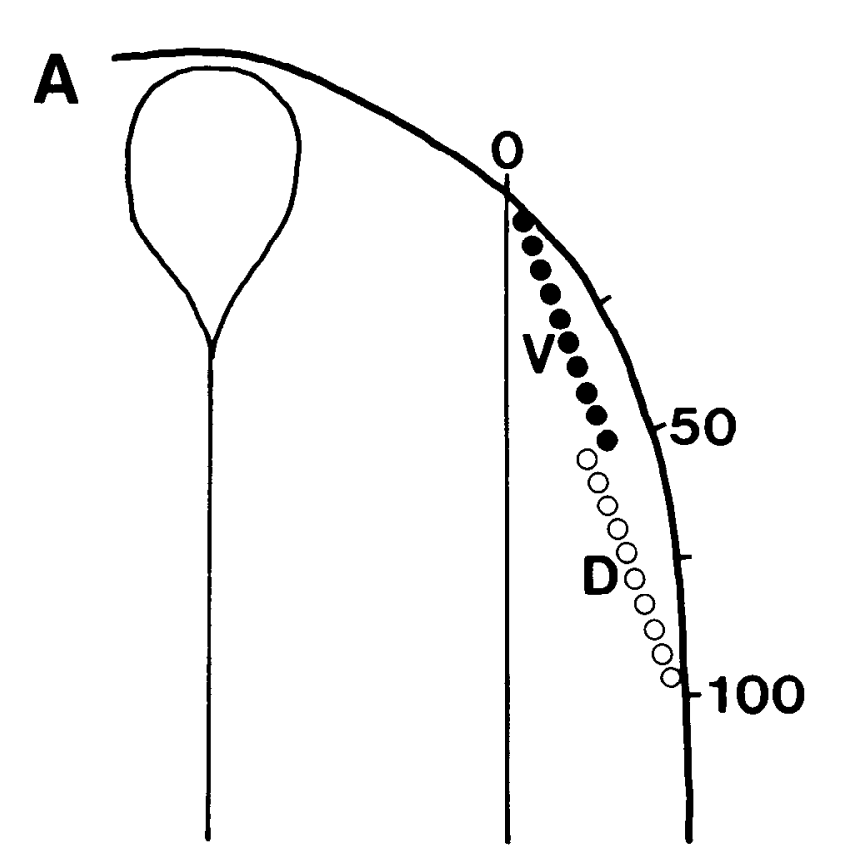

ventral and more lateral part of the tectum (see Figs. 6 , $12 A$, and 13 ). The terminals of fibers from the dorsal third of the retina extend, on average, across the ventral half $(\sim 50 \mu \mathrm{m})$ of the tectal neuropil: the mean dorsal border of the label lies $53 \pm 12 \mu \mathrm{m}$ from the origin (see Table II and Fig. 14A). Eleven of 40 cases showed grains distributed over the entire dorsoventral extent, although these usually exhibited a local density in the appropriate ventral half of the tectum, indicating a degree of specific innervation. This spread could be ascribed to spread of label within the retina since the retinas of samples showing such diffuse tectal labeling exhibited more extensive label than did those showing restricted projections. The larger amount of label in these retinas was due either to a larger region of the presumptive retina having undergone incubation (in excess of half), or to leakage from the $\left[{ }^{3} \mathrm{H}\right]$ proline-incubated part.

Fibers from ventral retinal thirds in series $\mathrm{Ib}$ projected to the dorsal, more medial part of the tectum (see Figs. $6,12 C, 13$, and $14 A$ ) and extended further caudally than did dorsal projections. From a total of 28 cases at stages 40 and $41,19(68 \%)$ were restricted to the dorsal tectal half; 8 cases showed diffuse tectal label which, like series Ia, was usually more dense in the appropriate (dorsal) half and, again, could be attributed to retinal spread. The ventral third of the retinal projection was confined, on average, to the dorsal $50 \mu \mathrm{m}$ of the tectal neuropil (Table II and Fig. 14A). The labeled dorsal border (53 \pm $12 \mu \mathrm{m}$ ) of the population of fibers from the dorsal third of the retina coincides with the ventral labeled border $(52 \pm 11 \mu \mathrm{m})$ of fibers from ventral retinal thirds showing

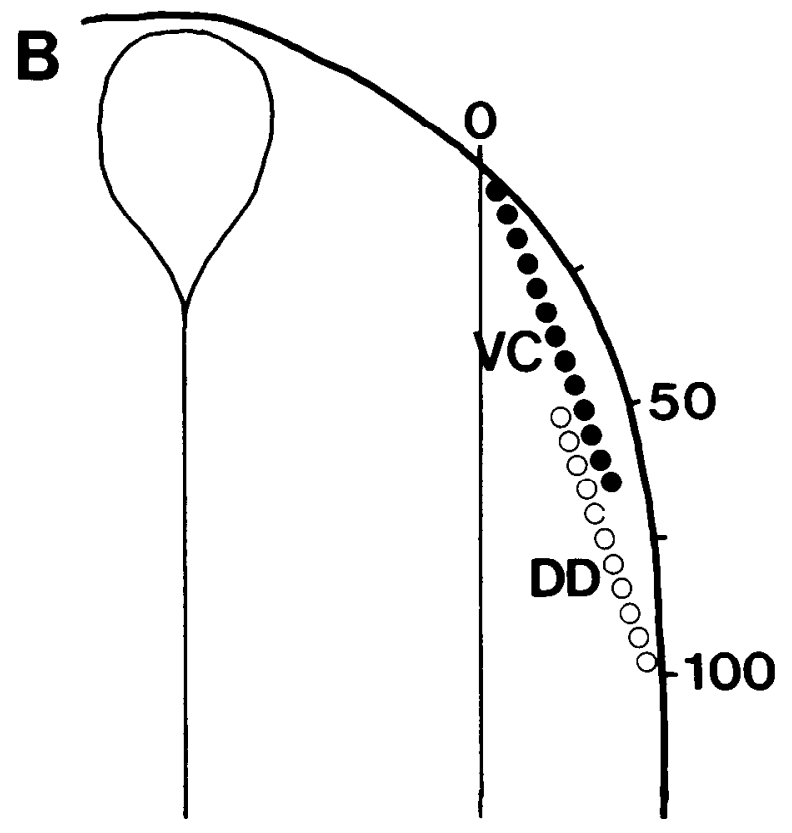

\section{NORMAL}

\section{HETEROCHRONIC}

Figure 14. Diagrammatic representation of the topographic patterns of tectal innervation at stages 40 and 41 (and 42 for delayed dorsal projections $(D D)$ ) using the quantitation presented in Table II. The mean extents of tectal label are shown for $(A)$ ventral $(V$, solid circles) and dorsal $(D$, open circles) labeled thirds of the retina, and $(B)$ ventral control projections $(V C$, solid circles) and delayed dorsal projections ( $D D$, open circles). 
that there is little overlap between these two retinal thirds, as illustrated in Figure 14A.

Ventral control eyes (series IIIa) showed a type of distribution of tectal label similar to that of the ventral third eyes (Fig. 12D) except that the mean ventral border of the label was shifted ventrally by some $10 \mu \mathrm{m}$ (see 'Table II and Fig. 14B). This shift, which resulted in a greater tectal coverage (Table II), corresponds with the larger fraction of retina that was labeled (half versus third) in this control group. From a total of 14 cases, 11 showed restricted label.

The projections from delayed dorsal half retinas in series II were topographically similar to those of the dorsal retinal thirds in series Ia (Figs. $12 B$ to $14 B$ ). Of 32 tecta in which labeled fibers were present (stages 40 to 42$), 21(65.5 \%)$ were restricted to the ventral part. The dorsal border of label was shifted some $10 \mu \mathrm{m}$ dorsally in the tectum, making the mean tectal coverage slightly higher than in the dorsal retinal third group (48 $\mu \mathrm{m}$ versus $53 \mu \mathrm{m})$. This correlated with the different sized fractions of retina labeled in the two experiments: a half in series II versus a third in series I (see Fig. 1). The percentage of diffuse tectal label in series II was slightly higher than that in series Ia $(34.4 \%$ versus $27.5 \%$ ), and this also probably reflected the larger amount of retina incubated originally and/or the higher incidence of retinal spread seen in this heterochronic group (see "Eyes"). The mean extents of the delayed dorsal projections are shown in relation to those of the ventral control projections in Figure $14 B$ where the same sized fractions of the retina (half) were labeled in each experiment. There is an overlap of 15 to $20 \mu \mathrm{m}$.

Whole eye controls in series IIIa projected to the entire tectum (Figs. $12 \mathrm{E}$ and 13 ), except at the very beginning of tectal innervation, stage $37 / 38$, when label was restricted to ventral tectum. This initial restriction presumably reflected the early and exclusive arrival of the dorsal population of retinal fibers.

\section{Discussion}

To summarize briefly, the experiments demonstrated that: (1) there is a dorsal-to-ventral gradient in the early differentiation of the Xenopus eye rudiment with dorsal retinal ganglion cells being the first to send out axons. (2) Dorsal retinal fibers lead the ventral ones in their growth along the optic pathway at all stages of development and thus pioneer the route to the tectum. (3) The initial set of retinal axons arrives in the tectum in a defined sequence which matches the spatial pattern of the early map and, thus, could generate the early topographic order. (4) However, these temporal gradients of axonogenesis and target invasion are not critical for establishing topographic order since their disruption results in normal initial maps. Several issues arise from these results and are discussed below.

\section{Pattern of fiber outgrowth}

The results from the series I experiments showed that axons grow out of the newly differentiated eye cup in a stereotyped spatiotemporal sequence. The very first ganglion cell axons were seen to originate from the temporal part of the dorsal retina and grew along the optic pathway to the contralateral tectal rudiment roughly $6 \mathrm{hr}$ ahead of fibers from the ventral part of the retina. The real pattern of initial axonal outgrowth is probably graded from dorsal to ventral retina but appears discontinuous here, simply because outgrowth from the retinal extreme thirds, and not from central retina, was examined. Indeed, this was supported by the observation that, when central as well as dorsal and ventral retinal ganglion cells were labeled, as in the whole eye projections in series $\mathrm{IIIb}$, the tectum became labeled in its dorsal part a stage earlier than when ventral projections alone were labeled (stage 39 versus stage 40 ).

The pattern of retinal axonogenesis correlates with that of several other processes of eye maturation in Xenopus which occur along the same dorsoventral gradient: (1) the migration of cells into the optic vesicle from the optic stalk-presumptive dorsal retinal cells arrive first, ventral ones last (Holt, 1980); (2) the ventral migration of retinal pigment epithelial cells (see "Results;" Holt, 1980); (3) the expression of pigmentation which occurs first in dorsal and then in ventral retina; (4) the pattern of acetylcholinesterase staining in the developing retina (A. Hall, personal communication); and (5) the sequence of optic vesicle invagination to form the optic cup which begins dorsally and proceeds ventrally (Grant et al., 1980; Holt, 1982). Thus, the morphological characteristics of eye maturation seem to parallel the sequence of retinal ganglion cell axonogenesis.

The pattern of early axon outgrowth observed here appears to differ from the previously reported pattern of embryonic ganglion cell proliferation, which proceeds concentrically from central to peripheral retina in Xenopus (Jacobson, 1967). However, in Jacobson's (1967) study, the first ganglion cells analyzed came out of the cell cycle at stage 29 , at least $1 \mathrm{hr}$ after the differentiation of the first retinal axons at stage 28 (Cima and Grant, 1980). Therefore, the concentric pattern of retinal growth (Jacobson, 1967) seems to develop after an initial phase when dorsal retinal differentiation precedes that seen ventrally.

Similarly, the pattern of initial axon outgrowth differs from that of the mature retina where new axons are extended from annuli of ganglion cells added around the ciliary margin in fish and amphibians (Hollyfield, 1971; Straznicky and Gaze, 1971; Johns, 1977; also see Scholes, 1979; Bodick and Levinthal, 1980), although growth asymmetries do occur in the Xenopus retina (Beach and Jacobson, 1979).

The pathway taken by the initial population of axons across the midline, up the wall of the contralateral diencephalon, and to the opposite tectum was found to be highly stereotyped, and labeled fibers were not observed outside these normal trajectories as occurs after optic nerve regeneration in adult frog (Bohn and Stelzner, 1981), in fish (Springer, 1981), and in mammalian development (Bunt and Lund, 1979; Land and Lund, 1979). This rules out the possibility that the first axons grow randomly, finding their targets by a process of trial and error. 'l'hus, initial retinal axon outgrowth appears to be directed and, in this respect, resembles that of early motoneuron outgrowth from the chick spinal cord 
(Lance-Jones and Landmesser, 1981a) and of retinogeniculate fiber outgrowth in the cat (Shatz and Kliot, 1983).

\section{Sequence of tectal innervation}

Because of the temporal pattern of early eye development, the first population of optic axons grow into the tectum in a sequence which reflects their places of origin in the retina, and this, in fact, matches the development of the early map. The rostral tectum is innervated first in its ventrolateral part by fibers of dorsal and temporal retinal origin, and the dorsomedial, more caudal part begins to be innervated roughly $6 \mathrm{hr}$ later by ventral retinal fibers. A similar sequence of tectal innervation has recently been described in chick embryos (McLoon, 1982), and it is interesting that this early innervation pattern roughly matches the subsequent caudomedial pattern of tectal maturation and growth (Straznicky and Gaze, 1972; Currie and Cowan, 1974; Jacobson, 1977).

Simultaneous with the arrival of axons at the tectum at stage $37 / 38$, phototransduction begins in the Xenopus retina (Witkovsky et al., 1976) and, as recent behavioral results show, visually mediated startle responses begin (G. Recanzone, personal communication). Visual responses, recorded extracellularly from retinal terminals in the tectum, have first been detected $3 \mathrm{hr}$ later than this at stage 39 (Holt and Harris, 1983). Thus, it appears that receptor maturation, target innervation, and probably synaptogenesis are highly synchronized so that visual connections can be functional as soon as fibers arrive.

The tectum continues to accrue new optic nerve fiber inputs in a sequential manner throughout life (Straznicky and Gaze, 1972; Jacobson, 1977). However, the pattern of tectal cell addition does not match the topographic origins of arriving retinal axons (Gaze et al., 1979b), and to compensate for this, retinal terminals continuously change their positions throughout growth (Gaze et al., 1979b; Easter and Stuermer, 1982; Cook et al., 1983; Fraser, 1983). Therefore, the positions occupied by the initial population of retinal terminals seen here in the young tectal rudiment are not fixed but must follow the caudomedial growth of the tectum.

\section{Disrupted timing and topography}

The sequential nature of development of the retinotectal projection prompted the question of whether this in itself could generate topographic order in the tectum. It could be envisaged that the pioneering population of dorsal fibers take up ventral sites in the tectum simply because they arrive there first and that the later growing ventral fibers, constrained by the existing dorsal population, take up more dorsal positions in the optic tract and are delivered thus to the appropriate dorsal part of the tectum. This possibility was eliminated, however, by the heterochronic grafting experiments in series II. These showed that, when outgrowth from the dorsal retina was delayed so that dorsal axons arrived in the tectum 9 to $20 \mathrm{hr}$ later than normal, after ventral retinal fibers, the spatial pattern of target innervation was normal. The possibility that the young dorsal transplants had retarded the differentiation of the host ventral retina, such that the temporal relations within the retina had remained undisturbed, was ruled out by showing that the time course of ventral fiber outgrowth from the heterochronic eyes was normal. In addition, these control experiments (series IIIa) showed that, despite the absence of the pioneer population of dorsal retinal fibers, ventral "follower" fibers still grew to their appropriate target sites from the outset. These results, then, support the conclusion that the temporal order in which ganglion cell axons grow out from the retina and invade the tectum is not critical for appropriate target selection.

This is consistent with the finding that normal maps are formed in Xenopus after tectal innervation has been substantially delayed (Feldman et al., 1971). Similarly, the pattern of Mauthner cell innervation develops normally despite either precocious or retarded synaptogenesis (Leber and Model, 1981, 1982). By contrast, however, abnormal connections in terms of original place specificities are formed in the locust optic lobe when the normal sequence of innervation is disrupted by grafting pieces of presumptive photoreceptor tissue to temporally discrepant positions (Anderson, 1978; Nowell, 1981) and, in Daphnia, delayed photoreceptor differentiation affects the order of target cell recruitment (Macagno, 1981) and the choice of bundle that growing axons join (Flaster et al., 1982). These latter results, then, suggest that spatiotemporal factors are more important for establishing patterned nerve connections in the visual system of invertebrates than that of vertebrates.

Although the present results show that fiber terminal ordering remains the same in the tectum regardless of the time of ingrowth, they cannot descriminate whether growing axons select their appropriate positions in the tectum itself or at some point along the pathway before entering the tectum. Fiber ordering at the head of the optic nerve was mostly diffuse in the heterochronic group, and in a few cases inverted patterns were seen, suggesting the involvement of timing of axon outgrowth in shaping pathway order at least at this most distal level. However, the results obtained at the level of the optic tract were ambiguous (two showed order and two did not), so that it was not possible to determine whether fibers had positioned themselves correctly by this stage in the pathway. Previous studies have shown that developing (Straznicky et al., 1979) and regenerating (Attardi and Sperry, 1963) optic fibers do, indeed, select the appropriate brachium in which to enter the tectum. Thus, in the present study it is possible that the delayed population of growing dorsal retinal fibers was wrongly placed in the early part of the pathway (i.e., located ventrally in the optic nerve head instead of dorsally) and maneuvered into their correct positions later in the pathway. This would support the idea that, by dictating the spatial order in which fibers are delivered to the tectum, optic tract ordering is important in the gross ordering of the topographic map (Straznicky et al., 1981; Fawcett and Willshaw, 1982). However, a finer analysis of pathway ordering than the present method allowed is needed to resolve this question.

It may be concluded, then, that the temporal mechanics of normal development are not required for building the initial map. 'This is not to say that the timing of normal developmental events is unimportant; it may, in fact, be sufficient, but more likely it plays a permissive rather than a directive role in fiber ordering. 


\section{Other factors and mapping}

The present results are informative not only about the role of temporal factors but also about the influence of several other classes of factors in the early development of nerve connections.

\section{Pioneers}

Single pioneer axons have been observed to grow out in advance of the rest of the axons from afferent populations of neurons in arthropods (Lo Presti et al., 1973; Bate, 1976; Edwards, 1977). Their growth cones probe the environment, becoming dye-coupled to particular "guidepost" cells en route (Bentley and Caudy, 1983; Goodman et al., 1983), and it has been suggested that pioneer neurons lay down a path for later growing axons to follow (Bate, 1976). Indeed, selective killing of pioneer neurons (Edwards et al., 1981; but see also Keshishian and Bentley, 1983) or of the "guidepost" cells that they contact (Bentley and Caudy, 1983) results in a loss of normal pathways. Evidence for the existence of such pathfinding neurons in the developing vertebrate nervous system is absent. Nevertheless, the results presented here agree with those of Keshishian and Bentley (1983) in the grasshopper and show that normal nerve connections are formed after retarding the pioneer population of neurons, thus making it unlikely that the very first axons to pioneer the optic pathway play any special role in retinotectal development. A role for "guidepost" cells along the optic pathway remains a possibility in vertebrates.

\section{Fiber-fiber interactions}

Competition between fiber terminals appears to play a role in the fine ordering of visual connections (Hubel and Wiesel, 1965; Prestige and Willshaw, 1975; Meyer, 1983; Schmidt and Edwards, 1983). One possibility is that developing axons interact in a competitive way as they are growing to and first invading the tectum and that such interactions help give rise to initial fiber topography. On this basis, one would predict that the dorsal retinal fibers compete with the ventral retinal fibers for terminal space in the tectum from the outset of tectal innervation and, as a consequence, if either population were made to innervate the tectum in the absence of the other, each half projection would immediately spread to fill the entire tectum. However, the present results show that this does not happen either $(a)$ when the ventral set of fibers is induced to arrive in the tectum ahead of the dorsal half of the projection, or $(b)$ during normal development when dorsal retinal fibers arrive at the tectum first. This agrees with the recent results of Ferguson (1983a) showing that, after partial eye ablations, the projections of retinal fragments are restricted during initial innervation to their correct part of the tectum, as are those from compound double-ventral eyes examined at slightly later stages of development (Straznicky et al., 1981), and argues against the idea that competition between growing axons is involved in initial ordering. Since fiber competition seems to be mediated by neural activity (for review, see Harris, 1981), this conclusion supports the finding that retinal axons find the tectum and form at least grossly ordered maps in the absence of $\mathrm{Na}^{+}$mediated activity (Harris, 1980a).

\section{Active recognition}

Several recent studies on the retinotectal system demonstrate that active recognition, by optic afferents of their target areas in the tectum, is involved in the formation of the tectal map. Retinal fibers find their appropriate targets in the tectum when, for example, they grow from aberrant positions in the retina (Conway et al., 1980; Willshaw et al., 1983), after pieces of tectum have been rotated or translocated (Yoon, 1975, 1980) and after taking completely aberrant pathways (Hibbard, 1959; Harris, 1980b, 1982). Furthermore, they select their correct tectal brachium in a manner that cannot be unaccounted for by mechanical means (Straznicky et al., 1979, 1981; Fawcett and Gaze, 1982) and make complex neighbor exchanges as they approach the tectum (Scholes, 1979), indicating that simple fiber-following mechanisms are not sufficient for appropriate target selection. In agreement with these previous findings, the present results show that the topographic organization of the early projection is not generated by the accurately timed patterns of retinal fiber outgrowth and tectal innervation that occur early in development and, thus, support the idea that ingrowing retinal fibers actively recognize their appropriate positions either in the tectum or in the pathway or both. The selective nature of initial tectal innervation demonstrated here resembles that of initial motor innervation of the chick limb bud (Lance-Jones and Landmesser, 1980, 1981a, b; Ferguson, 1983b).

Although the results here do not demonstrate a cellto-cell level of recognition of the sort proposed by Sperry (1963), a rough idea of the precision of the initial map, at least along the dorsoventral axis, is given by the finding that fibers from a third of the retina are confined within the $50-\mu \mathrm{m}$ area of the correct tectal half. On a cell-to-cell scheme, one-third of the retinal projection should cover one-third ( $33 \mu \mathrm{m}$ ) of the tectum. The degree of accuracy of initial fiber ordering, then, is within $20 \%$ of the total tectal extent, which is about $20 \mu \mathrm{m}$. In view of the comparatively gross sampling methods used here (one-third of the projection is estimated to contain around 330 fibers at stage 40; Wilson, 1971), this level of precision is surprisingly fine. In adult goldfish the precision of terminal ordering seen with autoradiography is less than this, around $50 \mu \mathrm{m}$ (Meyer, 1980). This probably reflects the larger size of mature terminal arbors which can be as large as the entire stage 40 tectal rudiment in the adult frog (100 to $200 \mu \mathrm{m} \times 30$ to $50 \mu \mathrm{m}$; Potter, 1972).

In conclusion, axons from dorsal and ventral parts of the retina display differential behavior as demonstrated by their characteristic time courses of outgrowth, trajectories, and initial places of termination which must reflect intrinsic differences between them. These differences must arise very early in development since they are expressed by retinal tissue transplanted from the earliest eye bud stages (see series II experiments; Gaze et al., 1979b; Sharma and Hollyfield, 1980) and possibly reflect the different embryonic origins of dorsal and ventral retina (Jacobson and Hirose, 1978).

Thus, it can be envisaged that the topography of the map is "seeded" early in development by selective axonal growth so that populations of nascent axons, behaving 
according to their places of retinal origin, choose their appropriate domains either immediately on entering the tectum or earlier in the optic pathway. A finer degree of terminal ordering can then be achieved later in development, perhaps after the terminal arbors have reached a critical size, through activity-mediated interactions between fiber terminals (Meyer, 1983; Schmidt and Edwards, 1983). This two-step view of how topographic maps form during development corresponds with previous proposals (Law and Constantine-Paton, 1980; Fawcett and Willshaw, 1982).

\section{References}

Anderson, H. (1978) Postembryonic development of the visual system of the locust, Schistocerca gregaria. II. An experimental investigation of the formation of the retina-lamina projection. J. Embryol. Exp. Morphol. 46: 147-170.

Attardi, D. G., and R. W. Sperry (1963) Preferential selection of central pathways by regenerating optic fibres. Exp. Neurol. 7: $46-64$.

Bate, C. M. (1976) Pioneer neurons in an insect embryo. Nature 260: $54-56$.

Beach, D. H., and M. Jacolson (1979) Patterns of cell proliferation in the retina of the clawed frog during development. J. Comp. Neurol. 183: 603-614.

Bentley, D., and M. Caudy (1983) Pioneer axons lose directed growth after selective killing of guidepost cells. Nature 304 : $62-65$.

Bodick, N., and C. Levinthal (1980) Growing optic nerve fibres follow neighbors during embryogenesis. Proc. Natl. Acad. Sci. U. S. A. 77: 4374-4378.

Bohn, R. C., and D. J. Stelzner (1981) The aberrant retinoretinal projection during optic nerve regeneration in the frog. I. Time course of formation and cells of origin. J. Comp. Neurol. 196: 605-620.

Bonhoeffer, F., and J. Huf (1980) Recognition of cell types by axonal growth in vitro. Nature 288: 162-164.

Bonhoeffer, F., and J. Huf (1982) In vitro experiments on axon guidance demonstrating an anterior-posterior gradient on the tectum. EMBO J. 1: 427-431.

Bray, D. (1982) Filopodial contraction and growth cone guidance. In Cell Behaviours, R. Bellairs, A. Curtis, and G. Dunn, eds., pp. 299-317, Cambridge University Press, Cambridge, England.

Bunt, S. M. (1982) Retinotopic and temporal organization of the optic nerve and tracts in the adult goldfish. J. Comp. Neurol. 206: 209-266.

Bunt, S. M., and T. J. Horder (1977) A proposal regarding the significance of simple mechanical events, such as the development of the choroid fissure, in the organization of central visual projections. J. Physiol. (Lond.) 272: 10-12P.

Bunt, S. M., and R. D. Lund (1979) Development of a transient retino-retinal pathway in hooded and albino rats. Brain Res. 211: 399-404.

Bunt, S. M., T. J. Horder, and K. A. C. Martin (1978) Evidence that optic fibres regenerating across the goldfish tectum may be assigned termination sites on a "first come, first served" basis. J. Physiol. (Lond.) 241: 89-90P.

Cima, C., and P. Grant (1980) Ontogeny of the retina and optic nerve of Xenopus laevis. IV. Ultrastructural evidence of early ganglion cell differentiation. Dev. Biol. 76: 229-237.

Cima, C., and P. Grant (1982) Development of the optic nerve in Xenopus laevis. I. Early development and organization. J. Embryol. Exp. Morphol. 72: 225-249.

Conway, K., K. Feiock, and R. K. Hunt (1980) Polyclones and patterns in growing Xenopus. Curr. Top. Dev. Biol. 15: $217-$ 317.
Cook, J. E., E. C. C. Rankin, and H. P. Stevens (1983) A pattern of optic axons in the normal goldfish tectum consistent with the caudal migration of optic terminals during development. Exp. Brain Res. 52: 147-151.

Cooper, M. L., and J. D. Pettigrew (1979) The retinothalamic pathways in Siamese cats. J. Comp. Neurol. 187: 313-348.

Currie, J., and W. M. Cowan (1974) Some observations on the early development of the optic tectum in the frog (Rana pipiens), with special reference to the effects of early eye removal on mitotic activity in the larval tectum. J. Comp. Neurol. 156: 123-142.

Dawnay, N. A. H. (1979) 'Chronotopic' organization of the goldfish optic pathway. J. Physiol. (Lond.) 296: 13P.

Easter, S. S., and C. A. O. Stuermer (1982) Evidence for naturally occurring movements of retinal terminals in goldfish. Soc. Neurosci. Abstr. 8: 745.

Easter, S. S., Jr., A. C. Rusoff, and P. E. Kish (1981) The growth and organization of the optic nerve and tract in juvenile and adult goldfish. J. Neurosci. 1: 793-811.

Edwards, J. S. (1977) Pathfinding by insect sensory neurons. In Identified Neurons and Behaviour of Arthropods, G. Hoyle, ed., pp. 483-493, Plenum Press, New York.

Edwards, J. S., S. -W. Chen, and M. W. Berns (1981) Cercal sensory development following laser microlesions of embryonic apical cells in Acheta domesticus. J. Neurosci. 1: 250258.

Fawcett, J. (1981) How axons grow down the Xenopus optic nerve. J. Embryol. Exp. Morphol. 65: 219-233.

Fawcett, J. W., and R. M. Gaze (1982) The retinotectal fibre pathways from normal and compound eyes in Xenopus. J. Embryol. Exp. Morphol. 72: 19-37.

Fawcett, J. W., and D. J. Willshaw (1982) Compound eyes project stripes on the optic tectum on Xenopus. Nature 296: $350-352$.

Feldman, J. D., R. M. Gaze, and M. J. Keating (1971) Delayed innervation of the optic tectum during development in Xenopus laevis. Exp. Brain Res. 14: 16-23.

Ferguson, B. A. (1983a) Simultaneous elimination of normal fibre-fibre interactions and impulse activity does not prevent appropriate tectal innervation. Soc. Neurosci. Abstr. 9: 759.

Ferguson, B. A. (1983b) Development of motor innervation of the chick following dorsal-ventral limb bud rotations. J. Neurosci. 3: 1760-1772.

Flaster, M. S., E. R. Macagno, and R. S. Schehr (1982) Mechanisms for the formation of synaptic connections in the isogenic nervous system of Daphnia magna. In Neuronal Development, N. Spitzer, ed., pp. 267-296, Plenum Press, New York.

Fraser, S. C. (1983) Fibre optic mapping of the Xenopus visual system: Shift in the retinotectal projection during development. Dev. Biol. 95: 505-511.

Fujisawa, H., N. Tani, K. Watanabe, and Y. Ibata (1981) Retinotopic analysis of fibre pathways in amphibians. II. The frog Rana nigromaculata. Brain Res. 206: 21-26.

Fujisawa, H., N. Tani, K. Watanabe, and Y. Ibata (1982) Branching of regenerating retinal axons and preferential selection of appropriate branches for specific neuronal connections in the newt. Dev. Biol. 90: 43-57.

Gaze, R. M., and P. Grant (1978) The diencephalic course of regenerating retinotectal fibres in Xenopus tadpoles. J. Embryol. Exp. Morphol. 44: 201-216.

Gaze, R. M., and M. Jacobson (1963) A study of the retinotectal projection during regeneration of the optic nerve in the frog. Proc. R. Soc. Lond. (Biol.) 157: 420-448.

Gaze, R. M., and M. J. Keating (1970) Further studies on the restoration of the contralateral retinotectal projection of the contralateral retinotectal projection following regeneration of the optic nerve in the frog. Brain Res. 21: 183-195.

Gaze, R. M., M. J. Keating, and S. -H. Chung (1974) The 
evolution of the retinotectal map during development in Xenopus. Proc. R. Soc. Lond. (Biol.) 185: 301-330.

Gaze, R. M., J. D. Feldman, J. Cooke and S. -H. Chung (1979a) The orientation of the visuotectal map in Xenopus: Developmental aspects. J. Embryol. Exp. Morphol. 53: 39-66.

Gaze, R. M., M. J. Keating, A. Ostberg, and S. -H. Chung (1979b) The relationship between retinal and tectal growth in larval Xenopus: Implications for the development of the retinotectal projection. J. Embryol. Exp. Morphol. 53: 103143.

Goodman, C. S., J. A. Raper, S. Chang, and R. Ho (1983) Grasshopper growth cones: Divergent choices and labelled pathways. Prog. Brain Res. 58: 283-304.

Gottlieb, D. I., and W. M. Cowan (1972) Evidence for a temporal factor in the occupation of available synaptic sites during the development of the dentate gyrus. Brain Res. 41 : $452-456$.

Grant, P., E. Rubin, and C. Cima (1980) Ontogeny of the retina and optic nerve in Xenopus laevis. I. Stages in the early development of the retina. J. Comp. Neurol. 189: 593-613.

Gunderson, R. W., and J. N. Barrett (1980) Characterization of the turning response of dorsal root neurites toward nerve growth factor. J. Cell Biol. 87: 546-554.

Harris, W. A. (1980a) The effects of eliminating impulse activity on the development of the retinotectal projection in salamanders. J. Comp. Neurol. 194: 303-317.

Harris, W. A. (1980b) Regions of the brain influencing the projection of developing optic tracts in the salamander. J. Comp. Neurol. 194: 319-333.

Harris, W. A. (1981) Neural activity and development. Annu. Rev. Physiol. 43: 689-710.

Harris, W. A. (1982) The transplantation of eyes to genetically eyeless salamanders: Visual projections and somatosensory interactions. J. Neurosci. 2: 339-353.

Hibbard, E. (1959) Central integration of developing nerve tracts from supernumerary grafted eyes and brain in the frog. J. Exp. Zool. 141: 323-351.

Hollyfield, J. G. (1971) Differential growth of the neural retina in Xenopus laevis larvae. Dev. Biol. 24: 264-286.

Holt, C. E. (1980) Cell movements in Xenopus eye development. Nature 287: 850-852.

Holt, C. E. (1982) The development of the eye and its central connections in Xenopus. Ph.D. thesis, Universily of London.

Holt, C. E. (1983) The topography of the initial retinotectal map in Xenopus. Prog. Brain Res. 58: 339-345.

Holt, C. E., and W. A. Harris (1983) Order in the initial retinotectal map in Xenopus: A new technique for labelling growing nerve fibres. Nature 301: 150-152.

Horder, T. J. (1978) Functional adaptability and morphogenetic opportunism, the only rules for limb development? Zoon 6 : 181-192.

Horder, T. J., and K. A. C. Martin (1978) Morphogenetics as an alternative to chemospccificity in the formation of nerve connections. In Cell-Cell Recognition, 32nd Symposium of the Society for Experimental Biology, A. S. G. Curtis, ed., pp. 275-358, Cambridge University Press, Cambridge, England.

Hubel, D. H., and T. N. Wiesel (1965) Binocular interaction in the striate cortex of kittens reared with artificial squint. J. Neurophysiol. 28: 1041-1059.

Jacobson, M. (1967) Cessation of DNA synthesis in the retinal ganglion cells correlated with the time of specification of their central connections. Dev. Biol. 17: 219-232.

Jacobson, M. (1977) Mapping the developing retino-tectal projection in frog tadpoles by a double label autoradiograhic technique. Brain Res. 127: 55-67.

Jacobson, M. (1978) Developmental Neurobiology, Ed. 2, Plenum Press, New York.

Jacobson, M., and G. Hirose (1978) Origin of the retina from both sides of the embryonic brain: A contribution to the problem of crossing at the optic chiasm. Science 202: 637639.

Johns, P. R. (1977) Growth of the adult goldfish eye. III. Source of the new retinal cells. J. Comp. Neurol. 176: 343-358.

Keshishian, H., and D. Bentley (1983) Embryogenesis of peripheral nerve pathways in grasshopper legs. III. Development without pioneers. Dev. Biol. 96: 116-124.

Lance-Jones, C., and L. Landmesser (1980) Motoneurone projection patterns in the chick hind limb following early partial reversals of the spinal cord. J. Physiol. (Lond.) 302: 581-602.

Lance-Jones C., and L. Landmesser (1981a) Pathway selection by chick lumbrosacral motoneurones during normal development. Proc. R. Soc. Lond. (Biol.) 214: 1-18.

Lance-Jones, C., and L. Landmesser (1981b) Pathway selection by chick motoneurons in an experimentally altered environment. Proc. R. Soc. Lond. (Biol.) 214: 19-52.

Land, P. W., and K. R. Lund (1979) Development of the rat's uncrossed retinotectal pathway and its relation to plastic studies. Science 205: 698-700.

LaVail, J. H., R. A. Nixon, and R. L. Sidman (1978) Genetic control of retinal ganglion cell projections. J. Comp. Neurol. 182: 399-422.

Law, M. I., and M. Constantine-Paton (1980) Right and left eye bands in frogs with unilateral tectal ablations. Proc. Natl. Acad. Sci. U. S. A. 77: 2311-2318.

Leber, S. M., and P. G. Model (1981) Effect of delayed afferent arrival on synapse localization on the amphibian Mauthner cell. Soc. Neurosci. Abstr. 7: 177.

Leber, S. M., and P. G. Model (1982) Normal localization of synapses on the amphibian Mauthner cell despite precocious synaptogenesis. Soc. Neurosci. Abstr. 8: 436.

Letourneau, P. C. (1982) Nerve fibre growth and extrinsic factors. Curr. Top. Neurobiol., pp. 213-254.

Lo Presti, V., E. Macagno, and C. Levinthal (1973) Structure and development of neuronal connections in isogenic organisms: Cellular interactions in the development of the optic lamina of Daphnia. Proc. Natl. Acad. Sci. U. S. A. 70: 433437.

Macagno, E. R. (1978) A mechanism for the formation of synaptic connections in the arthropod visual system. Nature (Lond.) 275: 318-320.

Macagno, E. R. (1981) Cellular interactions and pattern formation in the development of the visual system of Daphnia magna (Crustacea, Branchiopoda). II. Induced retardation of optic axon ingrowth results in a delay in laminar neuron differentiation. J. Neurosci. 1: 945-955.

McLoon, S. C. (1982) Evidence for sliding connections in the development of the retinotectal projection in the chick. Soc. Neurosci. Abstr. 8: 451.

Meyer, R. (1980) Mapping the normal and regenerating retinotectal projection of goldfish with autoradiographic method. J. Comp. Neurol. 189: 273-289.

Meyer, R. L. (1983) Tetrodotoxin inhibits the formation of refined retinotopography in the goldfish. Dev. Brain Res. 6 : 293-298.

Murphey, R. K., S. E. Johnson, and D. S. Sakaguchi (1983) Anatomy and physiology of supernumerary cercal afferents in crickets: Implications for pattern formation. J. Neurosci. 3: $312-325$.

Nieuwkoop, P. D., and J. Faber (1956) Normal Table of Xenopus Laevis (Daudin), Elsevier-North Holland Publishing Co., Amsterdam.

Nowell, N. S. (1981) Formation of the retina-lamina projection of the cockroach: No evidence for neuronal specificity. J. Embryol. Exp. Morphol. 62: 241-258.

Potter, H. D. (1972) 'I'erminal arborizations of retinotectal axons in the bullfrog. J. Comp. Neurol. 144: 269-284.

Prestige, M. C., and D. J. Willshaw (1975) On a role for competition in the formation of patterned neural connec- 
tions. Proc. R. Soc. Lond. (Biol.) 190: 77-98.

Rager, G. (1980) Development of the retinotectal projection in the chicken. Adv. Anat. Embryol. Cell Biol. 63: 1-90.

Roth, R. L. (1974) Retinotopic organization of goldfish optic nerve and tract. Anat. Rec. 178: 453.

Rugh, R. (1962) Experimental Embryology, Ed. 3, Burgess Publishing Co., Minneapolis.

Rusoff, A. C., and S. S. Easter (1980) Order in the optic nerve of goldfish. Science 208: 311-312.

Scalia, F., and V. Arango (1983) The antiretinotopic organization of the frog's optic nerve. Brain Res. 266: 121-126.

Scalia, F., and K. Fite (1974) A retinotopic analysis of the central connections of the optic nerve in the frog. J. Comp. Neurol. 158: 455-478.

Schmidt, J. T., and D. L. Edwards (1983) Activity sharpens the map during the regeneration of the retinotectal projection in goldfish. Brain Res. 269: 29-40.

Scholes, J. H. (1979) Nerve fibre topography in the retinal projection to the tectum. Nature 278: $620-624$.

Sharma, S. C., and J. G. Hollyfield (1980) Specification of retinotectal connections during development of the toad Xenopus laevis. J. Embryol. Exp. Morphol. 55: 77-92.

Shatz, C. J. (1983) The prenatal development of the cat's retinogeniculate pathway. J. Neurosci. 3: 482-499.

Shatz, C. J., and H. Kliot (1983) Prenatal misrouting of the retinogeniculate pathway in the Siamese cat. Nature 300: $525-529$.

Sperry, R. W. (1963) Chemoaffinity in the orderly growth of nerve fiber patterns and connections. Proc. Natl. Acad. Sci. U. S. A. 50: 703-710.

Springer, A. (1981) Normal and abnormal projections following the crush of one optic nerve in goldfish (Carrassius auratus). J. Comp. Neurol. 199: 87-95.

Straznicky, C., and R. M. Gaze (1971) The growth of the retina in Xenopus laevis: An autoradiographic study. J. Embryol.
Exp. Morphol. 26: 67-69.

Straznicky, C., and R. M. Gaze (1972) The development of the tectum in Xenopus laevis: An autoradiographic study. J. Embryol. Exp. Morphol. 28: 87-115.

Straznicky, C., R. M. Gaze, and T. J. Horder (1979) Selection of appropriate medial branch of the optic tract by fibres of ventral retinal origin during development and regeneration: An autoradiographic study in Xenopus. J. Embryol. Exp. Morphol. 50: 253-267.

Straznicky, C., R. M. Gaze, and M. J. Keating (1981) The development of the retinotectal projections from compound eyes in Xenopus. J. Embryol. Exp. Morphol. 62: 13-35.

Torrealba, F., R. W. Guillery, U. Eysel, E. H. Polley, and C. A. Mason (1982) Studies of retinal representations within the cat's optic tract. J. Comp. Neurol. 211: 377-396.

Walsh, C., E. H. Polley, T. L. Hickey, and R. W. Guillery (1983) Generation of cat retinal ganglion cells in relation to central pathways. Nature 302: 611-614.

Willshaw, D. J., J. W. Fawcett, and R. M. Gaze (1983) The visuotectal projections made by Xenopus 'pie-slice' compound eyes. J. Embryol. Exp. Morphol. 74: 29-45.

Wilson, M. A. (1971) Optic nerve fibre counts and retinal ganglion cell counts during development of Xenopus laevis (Daudin). J. Exp. Physiol. 56: 83-91.

Witkovsky, P., E. Gallin, J. G. Hollyfield, H. Ripps, and C. D. B. Bridges (1976) photoreceptor thresholds and visual pigment levels in normal and vitamin A-deprived Xenopus tadpoles. J. Neurophysiol. 39: 1272-1287.

Yoon, M. G. (1975) Re-adjustment of the original topographic polarity following reimplantation of rotated or inverted tectal tissue in adult goldfish. J. Physiol. (Lond.) 252: 137-158.

Yoon, M. G. (1980) Retention of topographic addresses by reciprocally translocated tectal re-implants in adult goldfish. J. Physiol. (Lond.) 308: 197-215. 